\title{
Paid parental leave and child health in Australia
}

\author{
Barbara Broadway \\ University of Melbourne \\ Guyonne Kalb \\ University of Melbourne \\ Daniel Kuehnle \\ FAU Universität Erlangen-Nürnberg \\ Miriam Maeder \\ FAU Universität Erlangen-Nürnberg
}

\section{Acknowledgments}

We thank the Group of Eight - DAAD Australian-German Research Cooperation Scheme for funding received for this project. The paper uses data from Growing Up in Australia: The Longitudinal Study of Australian Children (LSAC). LSAC is conducted in partnership between the Australian Government Department of Social Services (DSS), the Australian Institute of Family Studies (AIFS) and the Australian Bureau of Statistics (ABS). The findings and views reported in this paper are those of the authors alone and should not be attributed to the DSS, AIFS or ABS. The authors wish to thank two anonymous referees and participants of the 2013 LSAC-LSIC Conference in Melbourne as well as participants of the doctoral workshop at the University of Erlangen-Nuremberg for helpful comments.

Keywords: child health, parental leave, Australia, LSAC.

JEL Classification: I1

Corresponding author: Barbara Broadway, Melbourne Institute of Applied Economic and Social Research. The University of Melbourne. 111 Barry Street. Victoria 3010. Australia. Tel.: +61 39035 4565; Fax: +61 38344 2111. Email: b.broadway@unimelb.edu.au

\begin{tabular}{|l|l|}
\hline Word count: & 7574 \\
\hline Page count: & 26 \\
\hline Table count: & $6(+2$ in appendix $)$ \\
\hline Figure count: & $1(+1$ in appendix $)$ \\
\hline
\end{tabular}




\title{
Paid parental leave and child health in Australia
}

\begin{abstract}
Providing mothers with access to paid parental leave may be an important public policy to improve child and maternal health. Using extensive information from the Australian Longitudinal Study of Children (LSAC), we estimate how paid parental leave entitlements influences children's health up to age seven. Exploiting detailed information on children's health, family background, mothers' pre-birth work histories and mothers' health behaviours during pregnancy, we show that paid parental leave entitlements go together with a reduced probability of a child having multiple ongoing health conditions, but show no significant correlation with any single condition. We find that the reduction in multiple conditions is strongest for children from lower socio-economic backgrounds. Our study implies that the provision of paid parental leave for short periods is unlikely to substantially improve child health on average, but may potentially benefit the health of more disadvantaged children.
\end{abstract}

Keywords: child health, parental leave, Australia, LSAC.

JEL Classification: I1 


\section{Introduction}

Improving children's health is an important public policy issue. Not only is child health important in its own right, but recent research stresses the importance of child health for adult outcomes. For instance, Currie (2009) and Case and Paxson (2010) show that early child health can affect educational attainment and labour market outcomes later in life and Currie et al. (2010) find that the effect on schooling outcomes works primarily through future health outcomes. This finding is consistent with the framework by Cunha and Heckman (2007) who hypothesise that child health dynamically interacts with other forms of human capital in the process of human capital accumulation. Thus, public policy may be able to improve children's long-term educational outcomes, occupational choices, and future incomes by addressing early child health inequalities.

This paper examines the relationship between mothers' access to paid parental leave, and child health outcomes. Parental leave schemes are one public policy tool that could directly impact on children's health for different reasons. First, parental leave could increase the amount of time a child spends with her parents instead of other informal or formal carers. Depending on whether parents provide better care than other carers, the amount and quality of time spent together may have positive or negative effects. Second, parental leave rights often specifically aim to decrease parental stress levels by increasing income and job security to alleviate parent's worries about their future career or their ability to financially provide for their family. If parental leave indeed reduces parental stress, parental health might benefit (Chatterji and Markowitz, 2005) and the quality of time the infant gets to spend with their parents may improve. Finally, since breastfeeding correlates with improved child health outcomes (World Health Organization 
and Unicef, 2003), parental leave rights might improve child health through prolonged breastfeeding. This paper tests whether a positive relationship between paid parental leave rights and a range of child health outcomes exists; and if so, whether this relationship is mediated through a reduction in time the child spends with carers other than the parents, through a reduction in parental stress levels and improvement of their mental health, and/or through breastfeeding.

Only few studies examine whether parental leave entitlements affect child health. Using aggregated macro data and between-country variation in parental leave schemes, studies such as Winegarden and Bracy (1995), Ruhm (2000), Tanaka (2005), and Engster and Stensöta (2011) find positive associations between parental leave rights and child health, but also stress the need for evaluations based on micro-data. We know of only three recent studies using micro-data to examine the effect of parental leave on child health. Similar to our approach, Berger et al. (2005) use propensity score matching and find a negative association between early return to work and some child health outcomes, including immunisations, in the US. Baker and Milligan (2008) exploit a Canadian reform that extended job-protected paid parental leave from about 6 to 12 months. Combining a regression-discontinuity with a difference-in-difference design, they find no consistent effect on child health, but show that the reform increased the duration of breastfeeding. Third, Rossin (2011) evaluates the effects of unpaid leave in the US (Family and Medical Leave Act). Using a difference-in-difference strategy, the study finds small positive effects mainly for college-educated and married women who spend more time at home during the first few months of their child's life. ${ }^{1}$

\footnotetext{
${ }^{1}$ Another recently emerging strand of the literature evaluates the effects of parental leave rights on long-term education and labour market outcomes: e.g., Baker and Milligan (2010), Liu and Skans (2010), Rasmussen (2010), Carneiro et al. (2011), Dustmann and Schönberg (2012), Danzer and Lavy (2013). These studies usually find no or only modest effects on children's outcomes, except Carneiro et al. (2011) who find a positive effect of a Norwegian reform in 1977 on earnings at age 30. The main mechanism appears to be an increase in the time spent by mothers with their children.
} 
The purpose of this paper is to examine the association of paid parental leave with different measures of child health in Australia. Our treatment consists of having access to any paid parental leave compared to having no access to paid parental leave. We extend and contribute to the literature in several ways. First, we provide new evidence for the association, and potentially the effect, of paid parental leave with/on child health outcomes in the first 7 years after birth. Second, we provide a detailed analysis of the transmission mechanisms that may account for the observed relationship, such as breastfeeding, childcare arrangements and parental health. Finally, since the utilisation of paid parental leave rights is likely to vary across education levels and income groups, we examine more closely how parental leave rights impact on children's health for different subgroups. Moreover, differences in care quality may depend on parental income and education which largely determine parents' financial resources to afford care services. Education and income might also affect which transmission mechanisms account for the potential effect on health. We explore such heterogeneities to determine which groups might benefit the most from paid parental leave legislation.

Although we cannot identify the effect of paid parental leave on child health conclusively in the absence of a reform, we exploit within-cohort variation in paid parental leave coverage to estimate the potential "effect" with reasonable confidence. To address selection bias, we apply a propensity score matching approach that exploits exceptionally rich information from the Longitudinal Study of Australian Children (LSAC) on children's health outcomes, at birth and at later ages, together with mothers' and families' characteristics, and pre-birth employment histories. Importantly, we have rich information on mothers' health behaviours during pregnancy and the children's health at birth, which we use as proxies for mothers' expectations about and preferences for their children's health. If uncontrolled, these could be major confounding fac- 
tors in selection into paid parental leave eligibility. Such detailed information is not commonly available in most datasets, yet is crucial to overcome the likely selection bias caused by unobserved heterogeneity. We examine children's health outcomes at ages one, three, five and seven.

We find very similar results for having access to paid parental leave (versus no access) to Baker and Milligan's (2008) study on the extension of paid parental leave: overall, there is no consistent pattern in the association of paid parental leave rights with a child's risk of suffering from any specific condition. However, we find that paid parental leave rights are associated with a substantially reduced risk of suffering from multiple health conditions. The association is stronger for children from lower socio-economic backgrounds, as measured by parental education, and it lasts well into a child's first years of school. Since employer-provided paid leave is typically granted to high-income and/or high-education parents, this result suggests that universal, government-provided paid parental leave rights have an important advantage over voluntary, employer-paid parental leave rights through reaching disadvantaged families who benefit most from paid parental leave. Our analysis of potential transmission mechanisms yields no clear answer to the question where the advantageous health correlation stems from: although paid parental leave substantially increases breastfeeding duration, this does not explain the improvement in children's health. This is again similar to the findings by Baker and Milligan (2008). Furthermore, neither parental health nor childcare utilisation explains the observed relationship.

The paper proceeds as follows. In section 2 we discuss the institutional framework governing parental leave legislation in Australia. Section 3 discusses the data and variables used in the analysis, and presents some descriptive statistics. Section 4 presents the empirical framework. 
Section 5 presents and discusses the main results. We conclude and discuss the paper's policy and general implications in section 6 .

\section{Institutional framework}

Similar to other OECD countries, Australia provides two types of parental leave to support parents of new-born babies. Since the introduction of the Workplace Relations Act 1996, all parents who are the primary carer of a new-born baby can claim up to 12 months of unpaid leave. The scheme entitles all employees, who were continuously employed with the same employer for a minimum of twelve months before giving birth, to unpaid parental leave and a return to their previous (or a comparable) position afterwards. Unpaid leave entitlements are thus near universal for working women, with no regional variation in coverage in the period of analysis for this study (i.e. after 2003). Mothers' pre-birth employment histories almost exclusively drive individual variation in eligibility.

Second, some parents can also claim paid leave which replaces some income during the period of leave taking. At the time the children included in this study were born (in 2003), paid parental leave was up to the employer and employee to negotiate. ${ }^{2}$ As a result, paid parental leave provisions are more likely to be granted to high-paid and highly educated parents. The Workplace Gender Equality Agency (WGEA) reports that $51.7 \%$ of employers provided some paid parental leave to some of their employees with an average duration of 9.7 weeks in 2012 (WGEA, 2013). ${ }^{3}$ In 2003, only 36\% of employers had provided paid leave (Equal Opportunity for Women in the Workplace Agency, 2010). ${ }^{4}$ Coverage varies greatly across industries: in

\footnotetext{
${ }^{2}$ Only employees in the public sector were legally entitled to paid leave, although provisions vary across states.

${ }^{3}$ The numbers relate to organisations with 100 employees or more.

${ }^{4}$ In 2011, Australia introduced a universal paid parental leave scheme funded by the Australian government that pays 18 weeks of minimum wage and complements the employer-paid parental leave. However, the recent timing and limited data availability mean that longer-term health effects cannot be evaluated yet.
} 
2012, from $89.3 \%$-coverage in electricity, gas, water and waste services to $17.2 \%$ in accommodation and food services. The average duration of leave, in case any is provided, is more uniform across industries; with the lowest average duration being 7.3 weeks in agriculture, forestry and fishing, and the highest average duration of 13.0 weeks in education and training (WGEA, 2012). ${ }^{5}$

This level of paid parental leave coverage is low by international comparison. It falls well short of the standard set by the International Labour Organization (ILO) Maternity Protection Convention (Convention No. 183), which requires that member states ensure access to at least 14 weeks of leave at a minimum of two thirds of previous earnings universally to all mothers. Many developed nations grant access to paid parental leave in excess of two-thirds of previous earnings or even at full earnings, for periods of at least 14 weeks and up to 6 months (ILO (International Labour Organization), 2014). ${ }^{6}$ However, there are other countries who like Australia do not meet the parental leave rights defined in the ILO convention, either in terms of duration or in terms of the associated payment. In the UK, mothers receive $90 \%$ of their pre-birth earnings for 6 weeks, and a flat-rate payment for another 32 weeks afterwards. Since coverage in Australia was not universal at the time when the study children were born, provisions fell well short of those provided in the UK. A similar situation is found in the US, where no provisions for paid parental leave are legislated. Nevertheless, while the period of leave that is typically accessible to Australian mothers (if any) is short, in particular compared to most European

\footnotetext{
${ }^{5}$ We could not find information on leave coverage or the duration of leave across industries in 2003. In 2009, average durations were shorter than in 2012 across the board, suggesting that in 2003 these durations were also shorter. The strong heterogeneity in coverage across industries in 2012 suggests that coverage in 2003 was unlikely to be uniform, although the exact nature of the heterogeneity may well have been different.

${ }^{6}$ Countries that provide a full replacement of pre-birth earnings for at least 14 weeks include Austria, Denmark, France, Germany, Greece, Luxembourg, Netherlands, New Zealand, Norway, Poland and Spain. Countries that provide payments in excess of two-thirds of previous earnings for 14 weeks include Belgium, Finland, Ireland, Italy, Romania, Sweden and Switzerland.
} 
countries, - in combination with unpaid leave - it should facilitate an increased breastfeeding duration, perhaps even up to 6 months. This being the age recommended by the World Health Organisation, it may be important for children's long-term health outcomes.

\section{Data and descriptive statistics}

\subsection{Data and sample}

We use data from the Longitudinal Study of Australian Children (LSAC) that started in 2003 and follows two cohorts of children over time (a 'child cohort': i.e. children aged 4-5 in 2003, and an 'infant cohort': i.e. children aged under 12 months in 2003). LSAC biennially documents children's physical, social and cognitive development together with a broad range of factors that impact on children's development (for details, see Soloff et al., 2005). LSAC interviews the children's parents and collects rich information on the parental socio-economic background, the broader family environment, parenting and health behaviours, type and quality of care arrangements, the children's activities, the children's health status, and nutrition. To identify the potential effect of paid parental leave from birth onwards, we restrict our analysis to all children in the infant cohort whose primary carer participated in Wave 1.5, which collects information on leave taking and the last pre-birth job. ${ }^{7,8}$ We follow these 3,549 children from wave 1 to wave 4; the children are 0 to 1 year old at the time of the first interview, and 6 to 7 years at the time of the last interview.

Since the provision of unpaid leave is near universal when conditioning on pre-birth employ-

\footnotetext{
${ }^{7}$ Wave 1.5 is a mail-out questionnaire between Wave 1 and Wave 2. The questionnaire does not directly ask about leave entitlement, but rather whether and what type of leave the mother took or did not take, as well as her reasons for doing so. From these questions, it is possible to derive whether a mother was entitled to paid leave independent of whether she used the entitlement. This procedure is described in detail in Hanel (2013).

${ }^{8}$ Information on 24 children who do not live with their mother is discarded.
} 
ment, we cannot disentangle the effects of unpaid parental leave from the effects of women's labour market history. We thus exclude children from the analysis whose mothers had not been working for the same employer in the twelve months before birth. This restriction reduces the sample of analysis to 2,234 children. As a result, the effect of eligibility for paid parental leave is estimated relative to the benchmark of having only unpaid leave entitlements, rather than no leave entitlements; and all women in the sample have had relatively stable employment prior to birth. If policy makers introduced a universal paid parental leave scheme for mothers with shorter tenure, or for mothers not working prior to birth, the potential effects could be different. However, this is an unlikely policy proposal, since parental leave programs around the world naturally target the population of working mothers. The potential effects of paid leave rights we identify are thus arguably of greater interest than an overall population effect would be.

We further restrict the analysis to children with non-missing values on health outcomes and on all the socio-economic and health control variables that we use, leaving us with 1,850 children in the first wave. The mothers of 1,008 children were eligible for paid parental leave.

\subsection{Child health outcomes}

LSAC contains detailed self-reported information about specific ongoing health conditions of the child. Since LSAC records current conditions, the prevalence of some of these conditions is quite low. Furthermore, LSAC documents whether children have had any respiratory problems in the past twelve months. Given how child health conditions develop over time, certain conditions become more or less common, and the conditions recorded in LSAC therefore change as the child grows older. We hence report the prevalence of most conditions in the descriptive analysis, whereas we focus on hearing problems and ear infections as well as respiratory con- 
ditions in the regression analysis. In addition, we examine two general indicators: an indicator variable for whether the child has any ongoing health condition, and another indicator variable for whether the child has multiple ongoing health conditions.

Table 1 presents the descriptive results, separately by eligibility of the mothers for paid parental leave. In all waves, the children with eligible mothers are less likely to have any of the specific health conditions, less likely to have any health condition at all, and less likely to have multiple health conditions. ${ }^{9}$ For most of the conditions, the difference is small and statistically insignificant. However, a marked and statistically significant difference between both groups of children is found in all waves for the probability of having multiple conditions; and at ages 2 to 7 for the probability of having ear infections (at the 10\%-level). In addition, children with eligible mothers have lower rates of chest problems, i.e., wheezing and asthma. These latter results are consistent with Baker and Milligan (2008) who find that mothers' access to extended paid parental leave specifically reduces the risk of respiratory conditions, including asthma, and ear infections. While multiple conditions are markedly less common in children whose mothers had access to paid parental leave, the probability of having just one health condition differs less between groups. The descriptive statistics imply that while paid parental leave rights do not greatly affect the common situation of having some illness, children whose mothers have leave entitlements are less likely to be more seriously unwell.

\subsection{Control variables}

As discussed in section 2, mothers who are eligible for paid parental leave receive higher pay, have higher education, and work in different industries and sectors prior to birth. Socio-

\footnotetext{
${ }^{9}$ There are very few exceptions to this finding, and the relevant differences are insignificant for these exceptions.
} 
economic characteristics, such as education, might have a direct effect on their children's health separate from the effect of paid parental leave. Unionisation and employers' characteristics might indicate access to other family policies (e.g. flexible working hours), which may be advantageous to children's health in their own right. ${ }^{10}$ Finally, preferences for jobs providing access to paid parental leave might correlate with other preferences, such as preferences for investments in health, which could directly affect their children's health. We deal with these confounding factors by adding a very extensive range of control variables when estimating the potential effect of paid parental leave on children's health. LSAC provides information on an extensive range of pre-birth characteristics that correlates both with child health and a mother's eligibility status. We use this information to reduce any existing selection bias as much as is possible given the data.

Our control variables are all measured prior to birth and can be grouped in three blocks. Specification 1 includes socio-economic characteristics of the parents such as age and education, salary, working hours (pre-birth), marital status, whether they were in a long-term relationship at the time of conception, age at first birth, and the presence and age of other children. These characteristics, which importantly also reflect time preference rates, impact on the mothers' and the families' capacity to make investments in their children's health. Specification 2 adds controls for mothers' health behaviours and health outcomes during the pregnancy, such as doctor visits, consumption of alcohol or tobacco, diabetes during pregnancy, and birth-related variables (birth weight, type and timing of birth). These variables reflect the stock of the mothers' health capital and preferences for health investments (e.g. risk preferences), and are likely

\footnotetext{
${ }^{10}$ Although ideally we would control for these family policies directly, this information is not available for the pre-birth employment. We believe that after controlling for the employment characteristics mentioned here, together with parental health outcomes, the remaining impact of these policies on child health should be modest.
} 
to be correlated with child health and the probability of choosing a job that provides access to paid parental leave. Including these characteristics, which are not commonly available in most datasets, is likely to eliminate a substantial portion of potential bias arising from selection into treatment. Specification 3 adds variables that directly impact on the mother's probability of receiving paid parental leave: firm size, whether the employer is in the public sector, and whether the mother is unionised. At the same time, these factors may increase a mother's probability of having access to other desirable family policies.

Table 2 shows the raw descriptive statistics for the full set of control variables and includes a number of commonly used statistical measures to gauge sample balance: the p-value for equality of means between treated and controls, the standardised bias, and the variance ratios. ${ }^{11} \mathrm{We}$ observe no statistically significant differences in health indicators between eligible and ineligible mothers, with a few exceptions related to alcohol and cigarette consumption. However, the bias and variance measures show that these differences pose no reason for concern. ${ }^{12}$ This indicates that the child's inherited health status and parental health preferences do not correlate strongly with maternal eligibility for paid parental leave. Any selection bias from endogenous sorting into jobs that offer paid parental leave rights towards mothers with higher preferences for health investments thus appears to be of less importance than one might think a priori.

However, differences in available resources and thus parental ability to invest in a child's health across the two groups of mothers become apparent when comparing the characteristics of their employers. Mothers who are entitled to paid parental leave are about $76 \%$ more likely to have worked for an employer with more than 500 employees prior to birth than mothers without

\footnotetext{
${ }^{11}$ The standardised bias should not be larger than 0.2 ; and the ratio of variances should not lie outside the interval $[0.5 ; 2]$. For more details, see Rubin (2001).

${ }^{12}$ In addition, the propensity score regression results show that, conditional on socio-demographic and employer characteristics, eligibility status does not partially correlate with alcohol or tobacco consumption at any stage of the pregnancy.
} 
such an entitlement. Eligible mothers are also more than twice as likely to be unionised, and more than three times as likely to have worked in the public sector. These stark differences in employer characteristics imply that a mother with access to paid parental leave may also have access to more other family-friendly workplace policies than a mother who does not enjoy paid parental leave provisions. ${ }^{13}$ To the extent that such policies have a direct effect on children's health, it is crucial to control for these personal and employer characteristics when estimating the effect of paid leave rights on children's health.

\subsection{Transmission mechanisms}

Based on the Grossman model (Grossman, 1972), we consider a basic child health production function. In this model, the current health of child $i$ at time $t$ depends on current health investments, a child's ability to convert these investments into health, the stock of health capital from the previous time $t-1$ subject to an age-dependent depreciation rate of the health stock $\delta(t)$ from one year to the next (where $\delta(t)>0$ ).

Paid parental leave possibly affects health investments in the time period just after birth in four main ways: first, it could facilitate prolonged breastfeeding; second, it could reduce parental stress and improve parents' mental health, thereby increasing parents' capacity to invest in their children's health; third, it may increase parental attention by giving parents more time with their newborn; fourth, it provides additional household income while the mother is on maternity leave. Since last period's health affects current child health, these early investments could have a pro-longed effect on health. In addition, paid parental leave could - through the same mechanisms - also directly and permanently alter the child's ability to convert investments

\footnotetext{
${ }^{13}$ We cannot include a control for industry in the last pre-birth job due to a large number of missing values.
} 
into health. In the first case, we would expect the effect of paid parental leave on child health to taper off over time; in the latter case, we would expect to see a lasting effect on child health. In this paper, we consider four transmission mechanisms that may work through either of these components either by improving the environment that children live in, or by increasing their ability to cope with a given environment.

First, Baker and Milligan (2008) show that mothers' delayed return to work increases the uptake and duration of breastfeeding which correlate positively with children's immune system and development (Armstrong and Reilly, 2002; Odijk et al., 2003; Kramer et al., 2008). ${ }^{14}$ Figure 1 shows the distribution of breastfeeding duration for mothers with and without access to paid parental leave. In both groups, a breastfeeding duration of three months is most common. However, compared to mothers without access to paid parental leave, mothers with access to paid leave are substantially more likely to breastfeed between six and twelve months, and less likely to breastfeed less than six months. ${ }^{15}$ We add controls for the duration of breastfeeding in the empirical analysis to investigate this pathway.

Second, we add controls for parental health that might affect both the inputs and production function. For instance, extended parental leave may improve parental health (physically and mentally) by reducing stress, or it might improve the relationship between the parents and in turn their health. Moreover, less stress after birth might potentially intensify the bond between parents and children. Alternatively, parental leave may improve the child's long-term ability to cope with health risks in their environment, rather than improving the environment the child

\footnotetext{
${ }^{14} \mathrm{~A}$ large body of medical literature examines the effects of breastfeeding, but most studies use within-cohort comparisons between mothers who do and mothers who do not breastfeed, and hence are likely to suffer from selection bias. The literature on the causal link between breastfeeding and child health is sparse: e.g., see Kramer et al. (2001) or Der et al. (2006).

${ }^{15}$ This is confirmed in Table A1 which shows that at all ages, children of eligible mothers are more likely to still be breastfed than children of ineligible mothers, with the largest difference in the probability of being breastfed past six months after birth.
} 
lives in. A range of early parenting behaviours might be improved if stress levels are reduced, from social interactions with the child to healthy feeding practices. ${ }^{16}$ To account for parental health, we include indicator variables for mothers' and fathers' physical and mental health in the years after birth. ${ }^{17}$

Third, a long-term change in the environment (inputs) might occur because paid parental leave increases the time mothers spend at home with their children. This may change parents' preferences away from non-parental childcare. To the extent that formal out-of-home care may expose a child to greater health risks, increased levels of parental care could improve children's health. To explore this potential transmission mechanism, we include some control variables for formal non-parental care utilisation. LSAC collects information on whether a child was looked after by anyone else than the main carer or that carer's partner at regular times. We include care provided at a day care centre or by a family day carer as formal out-of-home care. We also control for the total number of hours of formal childcare used per week.

Fourth, the additional income provided through paid maternity leave allows the mother to spend more time with her child without the associated reduction in household income. The literature documenting the gradient of child health with income (Kuehnle, 2014) shows that income significantly affects child health, although the size of the effect is quite modest. Unfortunately, we cannot test the importance of this mechanism here, since we do not have information on the amount (and value) of paid leave that a mother is eligible for.

\footnotetext{
${ }^{16}$ Postnatal depression, which may be seen as an extreme case of maternal 'stress', has been shown to negatively impact on parenting, feeding and interactions (Murray and Cooper, 1997; Beck, 1998; Cooper and Murray, 1998).

${ }^{17}$ The physical health indicators include dummy variables for whether the parent rates their own health to be 'very good' or 'excellent' versus 'poor', 'fair, or 'good'. Mental health is measured by the 'Kessler k-6 Depression Scale'. This scale is based on six items that describe a person's mental health status, each measured on a scale from 1 to 5 and uses the average response to combine the items in a single, continuous index. The items describe how often in the past four weeks a person felt i) nervous, ii) hopeless, iii) restless or fidgety, iv) worthless, v) that nothing could cheer them up, and vi) that everything was an effort.
} 


\section{Empirical strategy}

In the absence of a natural experiment, our strategy is to account for as many of the confounding factors driving selection into jobs with access to paid leave, as well as affecting child health directly, as is feasible. We use standard ordinary least squares (OLS) for our benchmark estimates, but also apply a propensity score matching approach (Rosenbaum and Rubin, 1983, 1985) to estimate the potential effect of paid parental leave on child health. Compared to OLS, matching techniques have the advantages of being more flexible, less prone to functional form misspecification, and of ensuring common support between treatment and control groups. However, both approaches rest on the key identifying assumption that we remove selection bias by controlling for all relevant characteristics that determine both paid leave eligibility and child health.

We commence by estimating the following model for each health outcome variable:

$$
\text { health }_{i t}=\alpha+\beta \text { eligp }_{i}+\gamma X_{i}^{s}+\epsilon_{i t}
$$

where health $h_{i t}$ refers to the health outcome of child $i$ at time $t$, eligp $_{i}$ is an indicator variable equal to one if the mother is eligible for paid parental leave, and zero otherwise. We estimate three different specifications of the model using vector $X_{i}^{s}(s \in 1,2,3)$ which contains the different sets of control variables corresponding to specifications 1-3 discussed in Section 3.3.

In addition to OLS, we use a propensity score matching approach. We estimate the propensity score using a probit model:

$$
p\left(X_{i}^{s}\right) \equiv \operatorname{Pr}\left(\operatorname{eligp}_{i}=1 \mid X_{i}^{s}\right)=E\left(\operatorname{eligp}_{i} \mid X_{i}^{s}\right)
$$


where $p\left(X_{i}^{s}\right)$ denotes the propensity score defined as the probability of being eligible for paid parental leave conditional on the pre-treatment characteristics $X_{i}^{s}$. The propensity score allows us to compare the realised health outcomes for children of mothers who have similar propensity scores, but differ in their actual eligibility for paid parental leave. We compute the 'average treatment effect on the treated' (ATT) as the difference in mean realised child health outcomes weighted by the propensity scores (Caliendo and Kopeinig, 2008):

$$
\tau^{A T T}=E_{P\left(X_{i}^{s} \mid e^{\left.e l i g p_{i}=1\right)}\right.}\left(E\left[\text { health }_{i t} \mid \text { eligp }_{i}=1, P\left(X_{i}^{s}\right)\right]-E\left[\text { health }_{i t} \mid \text { eligp }_{i}=0, P\left(X_{i}^{s}\right)\right]\right)
$$

The available matching estimators differ in the weights assigned to the control group individuals. Facing a trade-off between bias and efficiency, we use kernel-based matching (Heckman et al., 1998) as our preferred matching algorithm. Intuitively, kernel-based matching calculates a smoothed weighted average giving more weight to non-treated individuals that are more similar to the treated individual in terms of the propensity score.

To meet the identifying assumption, we match on all characteristics shown in Table 2. Kernel-based matching produces excellent results in balancing the sample, as shown in Table $3 .^{18}$ Out of the 81 included indicators, only two show significant differences between the samples of eligible and ineligible mothers at the $10 \%$-level. The variance ratio is very close to 1 for all characteristics, and the standardised bias never exceeds the commonly used threshold of 0.2. After matching, the samples of eligible and ineligible mothers no longer differ systematically in personal or employer characteristics, and mothers in the two groups are even less

\footnotetext{
${ }^{18}$ Figure A1 shows the distribution of propensity scores by mothers' eligibility status. We follow Smith and Todd (2005) and trim 10\% of the sample, removing eligible mothers from the sample who are in intervals where the density of the propensity score for eligible mothers differs most from the density of the propensity score for ineligible mothers (indicated by the white bars in Figure A1). After trimming, the condition of common support is fulfilled across the entire distribution.
} 
different in terms of their health during pregnancy than they were before matching. Using this matched sample, we estimate the potential effect of paid parental leave provisions on children's health for the treated group.

We can, of course, not rule out that other unobserved parental characteristics are correlated with a mother's probability of being eligible for paid parental leave, while also affecting parental health investments and/or a child's physical ability to translate these investments into good health. Parents may have information on their child's risk of having health problems that we cannot observe, and as a result sort into jobs that provide paid parental leave. However, it is important to note that for any such mechanism to bias our results, it must go beyond what is captured by their employment history and investments in earnings capacity (education, prebirth working hours and salary), by their fertility history (age and number of other children), and by their health investments during pregnancy; all of which are observed. Moreover, health investments during pregnancy were statistically identical for eligible and ineligible mothers even before the matching procedure (see Section 3.3); if parents were sorting into jobs based on expectations for their child's expected health status, one would expect them to also adjust other health behaviours during pregnancy. However, no indication of that was found.

\section{Estimation Results}

Table 4 shows how paid parental leave rights are associated with a reduced probability of a child suffering from adverse health conditions. Each row presents six estimates for the relationship between paid parental leave eligibility and a child health outcome. The estimates in the first three columns present results for equation (1), changing the set of regressors corresponding to specifications 1-3. Columns four to six repeat the estimation using kernel-based propensity 
score matching and gradually control for the same three sets of control variables. All models are estimated separately for each wave and each health outcome. Importantly, the point estimates for all conditions are remarkably stable across estimation methods and specifications. However, standard errors naturally increase for the matching estimators due to their greater flexibility, thereby reducing significance levels.

The regression results confirm that at all ages, except at age 2-3, children whose mothers are eligible for paid leave are significantly less likely to suffer from multiple health conditions. For children aged 0 to 1 year (Panel A), the estimated association varies between 2.1 percentage points (pp) and 2.5pp, and is significant at the 5\%-level for all OLS specifications. Two years later, when children are 2 to 3 years old, the estimated association decreases to around $1.3 \mathrm{pp}$ to $2.2 \mathrm{pp}$ and is estimated less precisely, becoming insignificant. Another two years later, when children are 4 to 5 years old, the association is stronger again at $4.7 \mathrm{pp}$ to $6.4 \mathrm{pp}$ and is significant for all specifications at the 1\%-level. Again two years later (Panel D), we estimate a reduction of between 3.1pp and 3.6pp across estimators, which is weakly significant in some specifications.

We also examine whether any specific health condition drives the above relationship. Overall, the estimated associations vary more strongly across ages and estimators, and are virtually zero for a number of health outcomes. Consistent with Baker and Milligan (2008), we find some evidence that paid parental leave rights are associated with a reduced incidence of ear infections at the age of 2-3. However, the relationship with ear infections is quite weak. Similarly, there is some weak evidence for a reduction in the occurrence of diagnosed asthma at age 2-3, and for a reduction in vision problems at age 4-5. However, no clear patterns emerge.

Our analysis supports the hypothesis that paid parental leave rights reduce the risk of suffering multiple health conditions, while the more common situation of having just one health 
condition is less affected. Overall we do not find a clear relationship for other specific conditions, or for the risk of suffering from at least one condition at any point in time. Although we cannot precisely identify the specific conditions behind the increase in multiple conditions, we find some weak evidence that ear infections/respiratory conditions/vision problems may contribute to this increase.

\subsection{Transmission mechanisms}

We have shown that paid parental leave rights are positively associated with children's health. In this section we explore whether the three sets of transmission mechanisms from section 3.4 may mediate the potential effect of paid parental leave rights. To disentangle the different factors, we add control variables that represent possible transmission mechanisms to our preferred specification (3) in three steps. ${ }^{19}$ If these variables indeed form (part of) the reason why paid parental leave rights improve children's health, the estimated effect of paid parental leave itself should decrease or disappear when such control variables are added to the estimation.

Adding controls for breastfeeding, the second column of Table 5 shows that the estimated associations of paid parental leave rights with child health remain virtually unchanged (compared to column 1, which is based on specification 3 in Table 4). This is similar to the findings by Baker and Milligan (2008), who conclude that breastfeeding duration increases but who find no impact on health from breastfeeding. This finding suggests that other factors, uncorrelated with breastfeeding duration, drive the measured association.

In a second step, we explore the role of parental health and add controls for measures of mothers' and fathers' physical and mental health in the years after birth: self-rated health and

\footnotetext{
${ }^{19}$ This specification includes the full set of controls, but applies OLS instead of the matching estimator. In the face of very stable point estimates across models for the full sample, we accept the slight decrease in flexibility of the functional form when using OLS instead of the matching estimator.
} 
the 'Kessler k-6 Depression Scale'. Adding these variables for parental health to the estimation hardly changes the estimated association of paid parental leave rights with child health, indicating that parental health does not explain the measured association.

In a third step, we test for childcare utilisation as a driving force behind the phenomenon. We add indicators whether a child had a formal childcare arrangement in the past month, and how many hours per week the child spent in these care arrangements. Again, adding these indicators to the estimation has no impact on the estimated association of paid parental leave rights with children's health. ${ }^{20}$

Our analysis provides no evidence that any of the three examined transmission mechanisms can explain the improvement of children's health associated with paid parental leave rights. Our analysis implies that improved health outcomes are due to unobserved transmission mechanisms that we cannot explore with the current data. These factors could include early parenting behaviours that improve a child's immune system or their overall ability to cope with health risks in their environment, on a long-term basis. This needs to be further examined in future research.

\subsection{Heterogeneities}

Because paid parental leave rights are associated with a lower probability of having multiple conditions, but exhibit no clear relationship with the risk of having at least any one condition, we hypothesise that a potential effect of paid parental leave rights varies across the health distribution and is stronger at its lower end. Given the literature documenting the gradient of child

\footnotetext{
${ }^{20}$ Although there are good theoretical reasons to assume a priori that the proposed transmission mechanisms will impact on children's health, empirically we find them to have relatively weak explanatory power - not only in explaining the impact of paid parental leave on children's health, but also in explaining children's health itself. The coefficients representing the proposed transmission mechanism are jointly significant at the 10-\% level in only 23 of the 71 regressions reported in Table 5. We find significant coefficients for indicators of childcare utilisation and parental health, but not for breastfeeding. Significant associations mostly occur in the first three waves (ages 0 to 5) for health outcomes related to hearing or breathing, or having any health problem at the time of the survey. We find a significant impact of childcare utilisation on hearing and breathing problems in all waves.
} 
health with income (Kuehnle, 2014), we expect heterogeneous effects of paid parental leave rights by parental socio-economic background. Moreover, paid parental leave rights can be seen as an increase in family wealth, or a relaxation of a family's budget constraint, either in terms of time or money. We hypothesise that the importance, and thus the impact, of an increase in wealth will be relatively greater for families with low overall wealth.

We estimate the relationship between paid parental leave rights and the probability of suffering multiple health conditions by various measures of parental background. First, we estimate it separately for children whose mother's income in her last job before birth was below and above the median income for mothers, followed by two estimations for children with fathers (parents) whose income (combined income) is below or above the median. ${ }^{21}$ Second, we divide children into those whose mothers (and fathers, respectively) do have a tertiary qualification versus those whose mothers/fathers do not. Splitting the sample of course leads to reduced sample sizes and increased standard errors, making it somewhat difficult to detect significant associations. ${ }^{22}$ However, a systematic pattern emerges nonetheless.

Table 6 presents the results based on the preferred estimator - the OLS estimations with the full set of controls (specification 3). The positive correlation of paid parental leave rights with good child health by parental background follows the same pattern across children's ages as for the full sample. However, the association is generally stronger for children whose parents do not have a tertiary degree (particularly for the father), and weaker for children with higher parental education. ${ }^{23}$ We also find stronger associations on average for children of low-income

\footnotetext{
${ }^{21}$ The median in all three cases is conditional on being a mother, father or parent couple.

${ }^{22}$ Estimating separately by mothers or fathers income based on median salary of course divides the sample in about two equally sized groups each; dividing the children in two groups along mothers' tertiary qualifications also creates two groups of nearly equal size. However, not so for fathers' education, about a third of all children in the sample have a father with a tertiary education and two thirds have a father without one (see Table 2).

${ }^{23}$ Column 1 in Table A2 contains the full set of estimation results analogous to column 3 of Table 4, using a sample restricted to children with at least one parent without tertiary qualification.
} 
fathers or from low-income families. Thus, our evidence suggests that the advantageous effect of paid parental leave rights, if any, occurs predominantly among children with lower parental socio-economic background - a group that has a substantially lower chance of having access to paid parental leave coverage. In a situation where employer-provided leave, determined by individuals' bargaining power in wage negotiations, is usually granted to groups that benefit the least, a case can be made for government-provided leave, either in a universal paid parental leave rights scheme, or in a scheme targeted at parents from a less advantaged background.

The results show similar patterns as for the full sample when exploring transmission mechanisms for the subgroup of children with at least one parent without tertiary education in columns 2 to 5 of Table A2.

The heterogeneity in the relationship between paid parental leave rights and child health provides some support that the observed relationship may be causal. It is what you would expect to see: families with fewer resources benefit more from receiving additional resources than families who are already better off at the start. If the relationship were entirely spurious, driven by self-sorting into jobs that provide paid parental leave, it would follow that predominantly mothers of low socioeconomic backgrounds sort into jobs according to paid parental leave status, given the stronger relationship observed for low-income and lower educated families. However, mothers of higher socio-economic backgrounds typically find themselves in a better labour market position which gives them greater bargaining power. They also have access to higher incomes (both their own and that of their partners) and are thus more likely to be able to afford trading away part of their earnings for leave entitlements. ${ }^{24}$ It thus seems implausible that sorting into jobs with paid parental leave access would occur more among women of low

\footnotetext{
${ }^{24}$ Edwards (2006) shows that women in Australia 'pay' for their leave entitlements in the form of wage reductions.
} 
socio-economic status than among women of high socio-economic status. While the observed heterogeneity does not conclusively establish causality, it is worth noting that no or the opposite pattern of heterogeneity would be expected if the effect were entirely spurious.

\section{Conclusion}

This paper examines the potential effect of paid parental leave rights on children's health, conditional on having access to unpaid parental leave. Previous evidence on the effects of paid parental leave rights on children's health is scarce and mostly based on aggregate macro-data, which makes it difficult to control for confounding factors in the absence of randomised control trials. Our analysis uses an extremely rich micro-data set, which allows us to control for a very broad range of confounding factors, to estimate the potential effect of paid parental leave rights.

Our analysis shows that paid parental leave rights are associated with a reduced probability of children having multiple health problems. Although we cannot pinpoint any specific, single condition, the relationship with multiple health conditions is strong: the association varying from a minimum of around 2pp at age 2-3 to a maximum of around 5pp at age 4-5. This implies that the potential effect is greater and thus of particular importance for children at the lower end of the health distribution. Moreover, the potential effect is stronger for children from lower socio-economic backgrounds, as measured in terms of parental education and income, which again implies that less advantaged children have greater health improvements if their parents are granted paid parental leave rights.

Our identification strategy cannot conclusively establish causality, as parents may sort into jobs that provide paid parental leave according to unobserved characteristics that also affect child health. However, if sorting into jobs alone is behind the estimated effects, rather than 
true causality, that sorting process i) would have to go beyond what can be captured by our very rich set of covariates, and ii) would have to occur more extensively among mothers of low socio-economic status, who have arguably less capacity to actually do so. The patterns of heterogeneity support an interpretation of our estimates as being driven - at least partly - by causality.

Furthermore, these heterogeneities strongly suggest that mandatory, government-funded paid parental leave rights have an important advantage over voluntary, employer-funded paid parental leave rights. Typically, voluntarily provided leave is more likely to be granted to higheducated parents and parents on high incomes who have greater bargaining power in negotiating their salary packages. Highly educated parents who have high incomes are also typically more likely to have healthier children. It is precisely the children of parents of lower socio-economic status who are likely to be in worse health, and who would benefit the most from having parents with access to paid parental leave. However, these parents are unlikely to be covered by voluntary schemes. In such a situation, a mandatory government-funded parental leave scheme can have a much greater average impact per child than a voluntary employer-provided scheme.

The longitudinal nature of the data allows us to follow children over time, up to age 6-7, and the advantageous health effects of paid parental leave rights appear to start fading out around the time when children start school. Thus, the potential health effect from paid parental leave lasts at least several years after its direct effect on the mother's presence at home has faded. The advantageous health effects were measured for relatively short durations of paid parental leave. Overall, mothers in Australia who have access to leave, only have about 9 weeks on average, which is a relatively short time. At the same time, this research shows that a short period of investment is linked to a potentially long period of public health returns (over and above 
other benefits such as improved mothers' labour market outcomes as reported by Broadway et al. (2016)). This further supports the desirability of a government-funded paid parental leave scheme.

\section{References}

Armstrong, J. and Reilly, J. J. (2002). Breastfeeding and lowering the risk of childhood obesity. The Lancet, 359(9322):2003-2004.

Baker, M. and Milligan, K. (2008). Maternal employment, breastfeeding, and health: evidence from maternity leave mandates. Journal of Health Economics, 27(4):871-887.

Baker, M. and Milligan, K. (2010). Evidence from maternity leave expansions of the impact of maternal care on early child development. Journal of Human Resources, 45(1):1-32.

Beck, C. T. (1998). The effects of postpartum depression on child development: A metaanalysis. Archives of Psychiatric Nursing, 12(1):12-20.

Berger, L. M., Hill, J., and Waldfogel, J. (2005). Maternity leave, early maternal employment and child health and development in the US. The Economic Journal, 115(501):F29-F47.

Broadway, B., Kalb, G., McVicar, D., and Martin, B. (2016). The impact of paid parental leave on labour supply and employment outcomes. Melbourne Institute Working Paper Series no. 9/16, University of Melbourne, Australia.

Caliendo, M. and Kopeinig, S. (2008). Some practical guidance for the implementation of propensity score matching. Journal of Economic Surveys, 22(1):31-72.

Carneiro, P., Loken, K. V., and Salvanes, K. G. (2011). A flying start? maternity leave benefits and long run outcomes of children.

Case, A. and Paxson, C. (2010). Causes and consequences of early-life health. Demography, 47(1):S65-S85.

Chatterji, P. and Markowitz, S. (2005). Does the length of maternity leave affect maternal health? Southern Economic Journal, 72(1):16.

Cooper, P. J. and Murray, L. (1998). Postnatal depression. BMJ (Clinical research ed.), 316(7148):1884-1886.

Cunha, F. and Heckman, J. (2007). The technology of skill formation. American Economic Review, 97(2):31-47.

Currie, J. (2009). Healthy, wealthy, and wise: Socioeconomic status, poor health in childhood, and human capital development. Journal of Economic Literature, 47(1):87-122.

Currie, J., Stabile, M., Manivong, P., and Roos, L. L. (2010). Child health and young adult outcomes. Journal of Human Resources, 45(3):517-548. 
Danzer, N. and Lavy, V. (2013). Parental leave and children's schooling outcomes: Quasiexperimental evidence from a large parental leave reform. Number No. w19452 in NBER Working Paper Series. National Bureau of Economic Research, Inc.

Der, G., Batty, G. D., and Deary, I. J. (2006). Effect of breast feeding on intelligence in children: prospective study, sibling pairs analysis, and meta-analysis. BMJ (Clinical research ed.), 333(7575):945.

Dustmann, C. and Schönberg, U. (2012). Expansions in maternity leave coverage and children's long-term outcomes. American Economic Journal: Applied Economics, 4(3):190-224.

Edwards, R. (2006). Maternity leave and the evidence for compensating wage differentials in australia. Economic Record, 82(258):281-297.

Engster, D. and Stensöta, H. O. (2011). Do family policy regimes matter for children's wellbeing? Social Politics: International Studies in Gender, State \& Society, 18(1):82-124.

EOWA (Equal Opportunity for Women in the Workplace Agency) (2010). Annual report 2009/10. Technical report, Equal Opportunity for Women in the Workplace Agency.

Grossman, M. (1972). On the concept of health capital and the demand for health. The Journal of Political Economy, pages 223-255.

Hanel, B. (2013). The impact of paid maternity leave rights on labour market outcomes. Economic Record, 89(286):339-366.

Heckman, J. J., Ichimura, H., and Todd, P. (1998). Matching as an econometric evaluation estimator. Review of Economic Studies, 65(2):261-294.

ILO (International Labour Organization) (2014). Maternity and paternity at work: Law and practice across the world. https://www.ilo.org/wcmsp5/groups/public/ ---dgreports/---dcomm/---publ/documents/publication/wcms_ 242615 . pdf. International Labour Office, Geneva [Online; retrieved 9/05/2016].

Kramer, M. S., Aboud, F., Mironova, E., Vanilovich, I., Platt, R. W., Matush, L., Igumnov, S., Fombonne, E., Bogdanovich, N., Ducruet, T., Collet, J.-P., Chalmers, B., Hodnett, E., Davidovsky, S., Skugarevsky, O., Trofimovich, O., Kozlova, L., and Shapiro, S. (2008). Breastfeeding and child cognitive development: new evidence from a large randomized trial. Archives of General Psychiatry, 65(5):578-584.

Kramer, M. S., Chalmers, B., Hodnett, E. D., Sevkovskaya, Z., Dzikovich, I., Shapiro, S., Collet, J.-P., Vanilovich, I., Mezen, I., Ducruet, T., Shishko, G., Zubovich, V., Mknuik, D., Gluchanina, E., Dombrovskiy, V., Ustinovitch, A., Kot, T., Bogdanovich, N., Ovchinikova, L., Helsing, E., and for the PROBIT Study Group (2001). Promotion of breastfeeding intervention trial (probit). Journal of American Medical Association, 285(4):413.

Kuehnle, D. (2014). The causal effect of family income on child health in the UK. Journal of Health Economics, 36:137-150. 
Liu, Q. and Skans, O. N. (2010). The duration of paid parental leave and children's scholastic performance. The BE Journal of Economic Analysis \& Policy, 10(1).

Murray, L. and Cooper, P. J. (1997). Editorial: Postpartum depression and child development. Psychological Medicine, 27(2):253-260.

Odijk, J., Kull, I., Borres, M. P., Brandtzaeg, P., Edberg, U., Hanson, L. A., Host, A., Kuitunen, M., Olsen, S. F., Skerfving, S., Sundell, J., and Wille, S. (2003). Breastfeeding and allergic disease: a multidisciplinary review of the literature (1966-2001) on the mode of early feeding in infancy and its impact on later atopic manifestations. Allergy, 58(9):833-843.

Rasmussen, A. W. (2010). Increasing the length of parents' birth-related leave: The effect on children's long-term educational outcomes. Labour Economics, 17(1):91-100.

Rosenbaum, P. R. and Rubin, D. B. (1983). The central role of the propensity score in observational studies for causal effects. Biometrika, 70(1):41-55.

Rosenbaum, P. R. and Rubin, D. B. (1985). Constructing a control group using multivariate matched sampling methods that incorporate the propensity score. The American Statistician, 39(1):33-38.

Rossin, M. (2011). The effects of maternity leave on children's birth and infant health outcomes in the united states. Journal of Health Economics, 30(2):221-239.

Rubin, D. B. (2001). Using propensity scores to help design observational studies: application to the tobacco litigation. Health Services and Outcomes Research Methodology, 2(3-4):169188.

Ruhm, C. J. (2000). Parental leave and child health. Journal of Health Economics, 19(6):931960.

Smith, J. and Todd, P. (2005). Does matching overcome lalonde's critique of nonexperimental estimators? Journal of Econometrics, 125(1-2):305-353.

Soloff, C., Lawrence, D., and Johnstone, R. (2005). LSAC technical paper no. 1: Sample design. Melbourne, Australia: Australian Institute of Family Studies.

Tanaka, S. (2005). Parental leave and child health across OECD countries. The Economic Journal, 115(501):F7-F28.

WGEA (2012). Industry Snapshots - All Industries. https://www.wgea.gov .au/ sites/default/files/All_Industries_2012.pdf. Workplace Gender Equality Agencey [Online; retrieved 24/11/2014].

WGEA (2013). Annual Report 2012-2013. https://www.wgea.gov.au/sites/ default/files/wgea_annual_report_12_13.pdf. Workplace Gender Equality Agencey [Online; retrieved 24/11/2014].

Winegarden, C. R. and Bracy, P. M. (1995). Demographic consequences of maternal-leave programs in industrial countries: evidence from fixed-effects models. Southern Economic Journal, pages 1020-1035. 
World Health Organization and Unicef (2003). Global strategy for infant and young child feeding. 
Figures and tables 


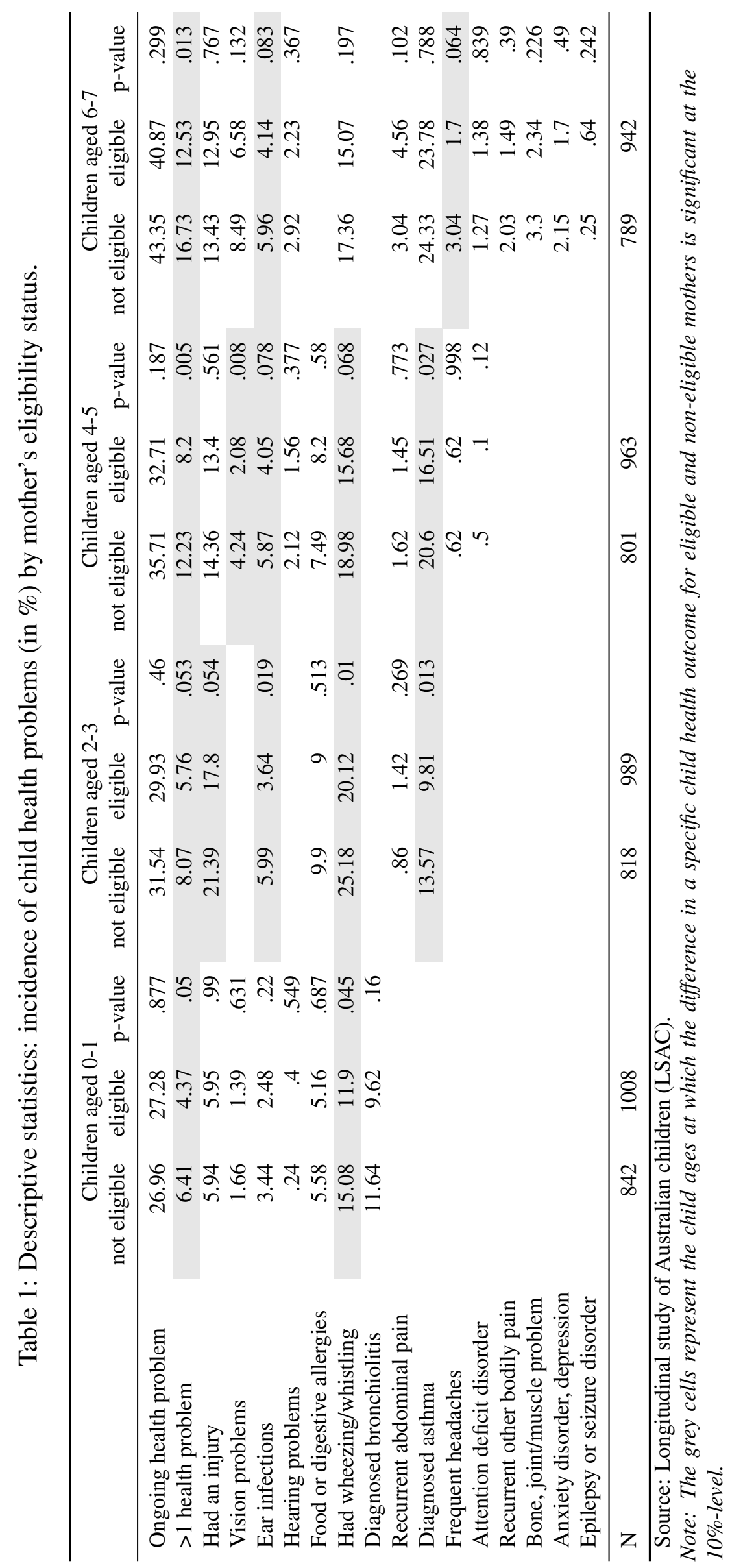


Table 2: Descriptives for characteristics by paid leave eligibility (in column $\%$ unless otherwise indicated)

\section{not eligible eligible p-value Bias VR}

Mother's characteristics

Age at birth (a): under 27 yrs, 2 mths

Age at birth: $27 \mathrm{yrs}, 3 \mathrm{mths}$ to $31 \mathrm{yrs}$

$\begin{array}{ccccc}19.71 & 15.38 & .01 & -.11 & .80 \\ 29.22 & 25.40 & .07 & -.09 & .92 \\ 28.15 & 31.25 & .15 & .07 & 1.06 \\ 22.92 & 27.98 & .01 & .12 & 1.12 \\ 58.31 & 54.96 & .15 & -.07 & 1.02 \\ 30.4 & 33.53 & .15 & .07 & 1.06 \\ 11.28 & 11.51 & .88 & .01 & 1.02 \\ 10.21 & 6.75 & .01 & -.12 & .68 \\ 16.15 & 10.91 & .00 & -.15 & .72 \\ 12.23 & 7.14 & .00 & -.17 & .60 \\ 16.75 & 9.33 & .00 & -.22 & .60 \\ 10.57 & 9.23 & .33 & -.04 & .88 \\ 20.07 & 32.94 & .00 & .29 & 1.41 \\ 6.77 & 9.13 & .06 & .09 & 1.31 \\ 7.24 & 14.58 & .00 & .24 & 1.87 \\ 84.2 & 86.61 & .14 & .07 & .87 \\ 1.07 & .79 & .54 & -.03 & .74 \\ 89.67 & 92.26 & .05 & .09 & .76 \\ 54.75 & 57.64 & .21 & .06 & 1.00 \\ 25.18 & 21.23 & .04 & -.09 & .91 \\ 20.07 & 21.13 & .58 & .03 & 1.04\end{array}$

Age at birth: $31 \mathrm{yrs}, 1 \mathrm{mths}$ to $34 \mathrm{yrs}, 4 \mathrm{mths}$

Age at birth: 34 yrs, 5 mths and over

Number of other children at birth: None

Number of other children at birth: One

Number of other children at birth: Two or more

No trade certificate, Year 12 not finished

No trade certificate, Year 12 finished

Trade certificate, Year 12 not finished

Trade certificate, Year 12 finished

Advanced diploma/ diploma

Bachelor degree

Graduate diploma/ certificate

Post-graduate degree

Australian born

Indigenous

Mother in a long-term relationship

Remoteness: Highly accessible

Remoteness: Accessible

Remoteness: Remote

Father's characteristics

No father/ no relationship with child's father

Child's father is mother's husband

Child's father is mother's de facto partner

Age at birth (a): under 28 yrs, 2 mths

Age at birth: $28 \mathrm{yrs}, 3 \mathrm{mths}$ to $32 \mathrm{yrs}, 5 \mathrm{mths}$

Age at birth: $32 \mathrm{yrs}, 6 \mathrm{mths}$ to $36 \mathrm{yrs}, 7 \mathrm{mths}$

Age at birth: $36 \mathrm{yrs}, 8 \mathrm{mths}$ and over

No trade certificate, Year 12 not finished

No trade certificate, Year 12 finished

Trade certificate, Year 12 not finished

\begin{tabular}{ccccc}
6.06 & 4.27 & .08 & -.08 & .71 \\
76.48 & 82.04 & .00 & .14 & .80 \\
17.46 & 13.69 & .03 & -.10 & .81 \\
20.07 & 14.88 & .00 & -.14 & .77 \\
28.15 & 29.96 & .39 & .04 & 1.04 \\
29.69 & 29.56 & .95 & .00 & 1.00 \\
22.09 & 25.60 & .08 & .08 & 1.10 \\
18.65 & 12.80 & .00 & -.16 & .72 \\
12.11 & 9.72 & .10 & -.08 & .84 \\
22.45 & 17.66 & .01 & -.12 & .83 \\
13.54 & 12.30 & .43 & -.04 & .92 \\
7.36 & 9.33 & .13 & .07 & 1.24 \\
14.61 & 20.73 & .00 & .16 & 1.33 \\
5.23 & 7.54 & .04 & .09 & 1.41 \\
6.06 & 9.92 & .00 & .14 & 1.59 \\
924.347 & 1052.431 & .00 & .22 & 1.13 \\
\hline \multicolumn{5}{c}{ Continued on next page }
\end{tabular}

Trade certificate, Year 12 finished

Advanced diploma/ diploma

Bachelor degree

Graduate diploma/ certificate

Post-graduate degree

Salary per week (in dollars) 
Table 2 - continued from previous page

\begin{tabular}{|c|c|c|c|c|c|}
\hline & not eligible & eligible & p-value & Bias & VR \\
\hline Salary per week missing & 2.61 & 2.38 & .75 & -.01 & .91 \\
\hline \multicolumn{6}{|l|}{ Pregnancy and birth } \\
\hline Alcohol 1st trimester: Never & 69.24 & 71.43 & .30 & .05 & .96 \\
\hline Alcohol 1st trimester: < once a week & 23.16 & 20.04 & .10 & -.08 & .91 \\
\hline Alcohol 1st trimester: $\geq$ once a week & 7.6 & 8.53 & .47 & .03 & 1.11 \\
\hline Alcohol 2nd trimester: Never & 60.81 & 60.02 & .73 & -.02 & 1.01 \\
\hline Alcohol 2nd trimester: $<$ once a week & 28.27 & 26.69 & .45 & -.04 & .97 \\
\hline Alcohol 2nd trimester: $\geq$ once a week & 10.93 & 13.29 & .12 & .07 & 1.19 \\
\hline Alcohol 3rd trimester: Never & 60.45 & 56.15 & .06 & -.09 & 1.03 \\
\hline Alcohol 3rd trimester: $<$ once a week & 28.98 & 29.27 & .89 & .01 & 1.01 \\
\hline Alcohol 3rd trimester: $\geq$ once a week & 10.57 & 14.58 & .01 & .12 & 1.33 \\
\hline Cigarettes 1st trimester: Never & 87.53 & 90.38 & .05 & .09 & .79 \\
\hline Cigarettes 1st trimester: < once a week & 1.54 & 1.19 & .51 & -.03 & .77 \\
\hline Cigarettes 1 st trimester: $\geq$ once a week & 10.93 & 8.43 & .07 & -.08 & .79 \\
\hline Cigarettes 2nd trimester: Never & 89.43 & 91.57 & .12 & .07 & .81 \\
\hline Cigarettes 2 nd trimester: $<$ once a week & 1.19 & 1.09 & .85 & -.01 & .92 \\
\hline Cigarettes 2 nd trimester: $\geq$ once a week & 9.38 & 7.34 & .11 & -.07 & .80 \\
\hline Cigarettes 3rd trimester: Never & 89.67 & 91.67 & .14 & .07 & .82 \\
\hline Cigarettes 3rd trimester: $<$ once a week & 1.43 & 1.39 & .95 & .00 & .97 \\
\hline Cigarettes 3rd trimester: $\geq$ once a week & 8.91 & 6.94 & .12 & -.07 & .79 \\
\hline Diabetes & 5.34 & 4.56 & .44 & -.04 & .86 \\
\hline High blood pressure requiring treatment & 9.38 & 6.15 & .01 & -.12 & .68 \\
\hline Stress, anxiety or depression & 16.27 & 14.48 & .29 & -.05 & .90 \\
\hline Took prescribed medicine & 27.32 & 28.67 & .52 & .03 & 1.03 \\
\hline$>=10$ medical visits/check-ups & 72.33 & 71.23 & .60 & -.02 & 1.02 \\
\hline Log(birth weight in grammes) & 8.119 & 8.128 & .26 & .05 & .67 \\
\hline Weeks of gestation & 39.182 & 39.226 & .62 & .02 & .89 \\
\hline On time? Yes/no & 89.90 & 89.09 & .57 & -.03 & 1.07 \\
\hline Birth type: Natural & 58.31 & 57.14 & .61 & -.02 & 1.01 \\
\hline Birth type: Cesarean & 31.59 & 31.25 & .87 & -.01 & 1.00 \\
\hline Birth type: Other & 10.10 & 11.61 & .30 & .05 & 1.13 \\
\hline \multicolumn{6}{|c|}{ Mother's pre-birth employment characteristics } \\
\hline Salary per week (in dollars) & 624.644 & 821.627 & .00 & .45 & 1.38 \\
\hline Hours per week: $<10$ hours/week & 4.75 & 4.27 & .62 & -.02 & .90 \\
\hline Hours per week: 10-19 hours/week & 14.37 & 11.61 & .08 & -.08 & .82 \\
\hline Hours per week: 20-29 hours/week & 16.63 & 17.66 & .56 & .03 & 1.05 \\
\hline Hours per week: 30-39 hours/week & 37.17 & 35.81 & .55 & -.03 & 1.00 \\
\hline Hours per week: 40-49 hours/week & 23.16 & 24.8 & .41 & .04 & 1.04 \\
\hline Hours per week: $\geq 50$ hours/week & 3.92 & 5.85 & .06 & .09 & 1.47 \\
\hline Size of employer: $\leq 5$ employees & 9.38 & 5.26 & .00 & -.16 & .55 \\
\hline Size of employer: 5-19 employees & 23.87 & 11.11 & .00 & -.34 & .53 \\
\hline
\end{tabular}


Table 2 - continued from previous page

\begin{tabular}{lccccc}
\hline & not eligible & eligible & p-value & Bias & VR \\
\hline Size of employer: 20-99 employees & 22.09 & 16.07 & .00 & -.15 & .78 \\
Size of employer: 100-499 employees & 14.85 & 14.98 & .94 & .00 & 1.01 \\
Size of employer: $\geq$ 500 employees & 29.81 & 52.58 & .00 & .48 & 1.14 \\
Union member & 20.19 & 43.55 & .00 & .52 & 1.28 \\
Public Sector & 16.27 & 54.76 & .00 & .88 & 1.28 \\
\hline $\mathrm{N}$ & 842 & 1008 & & &
\end{tabular}

Source: Longitudinal study of Australian children (LSAC), own calculations.

Notes: For each characteristic, bias denotes the standardised difference, and VR denotes the ratio of variances between eligible and ineligible mothers, see Rosenbaum and Rubin (1985).

a) age at birth of the mother and age at birth of the father are divided into four quartiles using data for all children in the LSAC Birth cohort. The age bounds listed are the cut-off points for each of these quartiles. 
Table 3: Descriptives for characteristics after matching by paid leave eligibility (in column \% unless otherwise indicated)

\begin{tabular}{|c|c|c|c|c|c|}
\hline & not eligible & eligible & $\mathrm{p}$-value & Bias & VR \\
\hline \multicolumn{6}{|l|}{ Mother's characteristics } \\
\hline Age at birth (a): under 27 yrs, 2 mths & 18.66 & 16.30 & .19 & -.06 & .88 \\
\hline Age at birth: $27 \mathrm{yrs}, 3 \mathrm{mths}$ to $31 \mathrm{yrs}$ & 26.33 & 25.99 & .87 & -.01 & .99 \\
\hline Age at birth: $31 \mathrm{yrs}, 1 \mathrm{mths}$ to $34 \mathrm{yrs}, 4 \mathrm{mths}$ & 31.34 & 31.39 & .98 & .00 & 1.00 \\
\hline Age at birth: 34 yrs, 5 mths and over & 23.68 & 26.32 & .19 & .06 & 1.06 \\
\hline Number of other children at birth: None & 53.19 & 54.74 & .51 & .03 & 1.01 \\
\hline Number of other children at birth: One & 34.61 & 33.26 & .54 & -.03 & .99 \\
\hline Number of other children at birth: Two or more & 12.19 & 12.00 & .90 & -.01 & .99 \\
\hline No trade certificate, Year 12 not finished & 7.29 & 7.49 & .87 & .01 & 1.03 \\
\hline No trade certificate, Year 12 finished & 10.18 & 11.45 & .38 & .04 & 1.15 \\
\hline Trade certificate, Year 12 not finished & 8.92 & 7.93 & .45 & -.04 & .88 \\
\hline Trade certificate, Year 12 finished & 10.07 & 10.24 & .90 & .01 & 1.02 \\
\hline Advanced diploma/ diploma & 8.12 & 9.58 & .27 & .05 & 1.18 \\
\hline Bachelor degree & 34.23 & 30.84 & .12 & -.07 & 1.02 \\
\hline Graduate diploma/ certificate & 8.62 & 9.03 & .76 & .01 & 1.04 \\
\hline Post-graduate degree & 12.56 & 13.44 & .58 & .03 & 1.05 \\
\hline Australian born & 88.16 & 86.01 & .17 & -.06 & 1.17 \\
\hline Indigenous & 1.24 & .88 & .46 & -.04 & .71 \\
\hline Mother in a long-term relationship & 90.27 & 92.07 & .18 & .06 & .82 \\
\hline Remoteness: Highly accessible & 54.95 & 56.28 & .57 & .03 & 1.00 \\
\hline Remoteness: Accessible & 20.61 & 22.47 & .34 & .05 & 1.07 \\
\hline Remoteness: Remote & 24.43 & 21.26 & .11 & -.08 & .92 \\
\hline \multicolumn{6}{|l|}{ Father's characteristics } \\
\hline No father/ no relationship with child's father & 5.23 & 4.30 & .35 & -.04 & .82 \\
\hline Child's father is mother's husband & 78.36 & 81.72 & .07 & .08 & .86 \\
\hline Child's father is mother's de facto partner & 16.41 & 13.99 & .15 & -.07 & .86 \\
\hline Age at birth (a): under 28 yrs, 2 mths & 18.01 & 15.42 & .14 & -.07 & .86 \\
\hline Age at birth: $28 \mathrm{yrs}, 3 \mathrm{mths}$ to $32 \mathrm{yrs}, 5 \mathrm{mths}$ & 29.7 & 29.74 & .99 & .00 & 1.00 \\
\hline Age at birth: 32 yrs, $6 \mathrm{mths}$ to $36 \mathrm{yrs}, 7 \mathrm{mths}$ & 30.37 & 29.96 & .85 & -.01 & .99 \\
\hline Age at birth: 36 yrs, 8 mths and over & 21.92 & 24.89 & .14 & .07 & 1.08 \\
\hline No trade certificate, Year 12 not finished & 15.01 & 13.55 & .37 & -.04 & .91 \\
\hline No trade certificate, Year 12 finished & 8.25 & 10.13 & .17 & .07 & 1.23 \\
\hline Trade certificate, Year 12 not finished & 20.25 & 18.83 & .45 & -.04 & .94 \\
\hline Trade certificate, Year 12 finished & 12.30 & 12.78 & .76 & .01 & 1.03 \\
\hline Advanced diploma/ diploma & 9.45 & 9.03 & .76 & -.01 & .96 \\
\hline Bachelor degree & 19.86 & 19.71 & .94 & .00 & 1.00 \\
\hline Graduate diploma/ certificate & 6.26 & 6.61 & .76 & .01 & 1.05 \\
\hline Post-graduate degree & 8.63 & 9.36 & .59 & .03 & 1.08 \\
\hline Salary per week (in dollars) & 1016.684 & 1027.247 & .70 & .02 & .98 \\
\hline
\end{tabular}


Table 3 - continued from previous page

\begin{tabular}{|c|c|c|c|c|c|}
\hline & not eligible & eligible & $\mathrm{p}$-value & Bias & VR \\
\hline Salary per week missing & 2.28 & 2.53 & .73 & .02 & 1.11 \\
\hline \multicolumn{6}{|l|}{ Pregnancy and birth } \\
\hline Alcohol 1st trimester: Never & 71.97 & 71.26 & .73 & -.02 & 1.02 \\
\hline Alcohol 1st trimester: < once a week & 19.14 & 20.70 & .41 & .04 & 1.07 \\
\hline Alcohol 1st trimester: $\geq$ once a week & 8.88 & 8.04 & .52 & -.03 & .92 \\
\hline Alcohol 2nd trimester: Never & 60.54 & 60.24 & .90 & -.01 & 1.00 \\
\hline Alcohol 2nd trimester: < once a week & 25.93 & 26.98 & .61 & .02 & 1.03 \\
\hline Alcohol 2nd trimester: $\geq$ once a week & 13.53 & 12.78 & .64 & -.02 & .96 \\
\hline Alcohol 3rd trimester: Never & 58.29 & 57.16 & 63 & -.02 & 1.00 \\
\hline Alcohol 3rd trimester: $<$ once a week & 27.94 & 29.19 & .56 & .03 & 1.03 \\
\hline Alcohol 3rd trimester: $\geq$ once a week & 13.77 & 13.66 & .95 & .00 & 1.00 \\
\hline Cigarettes 1st trimester: Never & 90.22 & 89.98 & .86 & -.01 & 1.03 \\
\hline Cigarettes 1st trimester: < once a week & .92 & 1.21 & .54 & .03 & 1.32 \\
\hline Cigarettes 1 st trimester: $\geq$ once a week & 8.86 & 8.81 & .97 & .00 & 1.00 \\
\hline Cigarettes 2nd trimester: Never & 91.32 & 91.41 & .95 & .00 & .99 \\
\hline Cigarettes 2 nd trimester: $<$ once a week & .78 & .99 & .63 & .02 & 1.27 \\
\hline Cigarettes 2 nd trimester: $\geq$ once a week & 7.90 & 7.60 & .81 & -.01 & .96 \\
\hline Cigarettes 3rd trimester: Never & 91.41 & 91.63 & .87 & .01 & .98 \\
\hline Cigarettes 3rd trimester: $<$ once a week & .93 & 1.21 & .56 & .03 & 1.30 \\
\hline Cigarettes 3rd trimester: $\geq$ once a week & 7.66 & 7.16 & 68 & -.02 & .94 \\
\hline Diabetes & 3.46 & 4.41 & .30 & .05 & 1.28 \\
\hline High blood pressure requiring treatment & 6.07 & 6.61 & 64 & .02 & 1.09 \\
\hline Stress, anxiety or depression & 15.39 & 14.98 & .81 & -.01 & .97 \\
\hline Took prescribed medicine & 25.11 & 28.08 & .15 & .07 & 1.08 \\
\hline$>=10$ medical visits/check-ups & 70.46 & 71.15 & .75 & .01 & .99 \\
\hline Log(birth weight in grammes) & 8.126 & 8.126 & .93 & .00 & .90 \\
\hline Weeks of gestation & 39.277 & 39.206 & .42 & -.04 & .98 \\
\hline On time? Yes/no & 89.32 & 89.10 & .88 & -.01 & 1.02 \\
\hline Birth type: Natural & 60.65 & 57.49 & .17 & -.06 & 1.02 \\
\hline Birth type: Cesarean & 29.81 & 31.61 & .41 & .04 & 1.03 \\
\hline Birth type: Other & 9.54 & 10.90 & .34 & .05 & 1.13 \\
\hline \multicolumn{6}{|c|}{ Mother's pre-birth employment characteristics } \\
\hline Salary per week (in dollars) & 742.894 & 773.568 & .17 & .06 & .78 \\
\hline Hours per week: $<10$ hours/week & 5.27 & 4.52 & .46 & -.03 & .86 \\
\hline Hours per week: 10-19 hours/week & 14.99 & 12.56 & .13 & -.07 & .85 \\
\hline Hours per week: 20-29 hours/week & 19.98 & 17.62 & .20 & -.06 & .92 \\
\hline Hours per week: 30-39 hours/week & 31.64 & 35.68 & .07 & .09 & 1.07 \\
\hline Hours per week: 40-49 hours/week & 22.03 & 24.34 & .24 & .05 & 1.07 \\
\hline Hours per week: $\geq 50$ hours/week & 6.10 & 5.29 & .46 & -.04 & .88 \\
\hline Size of employer: $\leq 5$ employees & 7.43 & 5.84 & .17 & -.06 & .76 \\
\hline Size of employer: 5-19 employees & 12.56 & 12.33 & .88 & -.01 & .99 \\
\hline
\end{tabular}


Table 3 - continued from previous page

\begin{tabular}{lccccc}
\hline & not eligible & eligible & p-value & Bias & VR \\
\hline Size of employer: 20-99 employees & 15.59 & 16.96 & .43 & .04 & 1.10 \\
Size of employer: 100-499 employees & 14.76 & 15.31 & .74 & .02 & 1.03 \\
Size of employer: $\geq$ 500 employees & 49.65 & 49.56 & .97 & .00 & 1.04 \\
Union member & 38.00 & 38.33 & .89 & .01 & .97 \\
Public Sector & 48.79 & 50 & .61 & .02 & .85 \\
\hline $\mathrm{N}$ & 842 & 908 & & & \\
\hline
\end{tabular}

Source: Longitudinal study of Australian children (LSAC), own calculations

Notes: For each characteristic, bias denotes the standardised difference, and VR denotes the ratio of variances between eligible and ineligible mothers, see Rosenbaum and Rubin (1985).

a) age at birth of the mother and age at birth of the father are divided into four quartiles using data for all children in the LSAC Birth cohort. The age bounds listed are the cut-off points for each of these quartiles. 
Table 4: Association of leave eligibility with child health

\begin{tabular}{|c|c|c|c|c|c|c|}
\hline & OLS (1) & OLS (2) & OLS (3) & Matching (1) & Matching (2) & Matching (3) \\
\hline \multicolumn{7}{|l|}{ Panel A: Children aged $0-1 ; \mathrm{N}=1,850$} \\
\hline \multirow[t]{2}{*}{ Ongoing health problem } & 0.001 & 0.004 & -0.005 & 0.007 & 0.012 & 0.011 \\
\hline & $(0.022)$ & $(0.022)$ & $(0.023)$ & $(0.024)$ & $(0.024)$ & $(0.030)$ \\
\hline \multirow[t]{2}{*}{$>1$ health problem } & $-0.025 * *$ & $-0.024 * *$ & $-0.025^{* *}$ & $-0.023^{*}$ & $-0.021 *$ & -0.022 \\
\hline & $(0.011)$ & $(0.011)$ & $(0.011)$ & $(0.012)$ & $(0.012)$ & $(0.016)$ \\
\hline \multirow[t]{2}{*}{ Vision problems } & -0.001 & 0.000 & -0.000 & 0.003 & 0.003 & -0.000 \\
\hline & $(0.006)$ & $(0.006)$ & $(0.007)$ & $(0.007)$ & $(0.007)$ & $(0.008)$ \\
\hline \multirow[t]{2}{*}{ Hearing problems/ear infections } & -0.004 & -0.002 & -0.007 & -0.005 & -0.003 & -0.004 \\
\hline & $(0.008)$ & $(0.008)$ & $(0.009)$ & $(0.009)$ & $(0.009)$ & $(0.012)$ \\
\hline \multirow[t]{2}{*}{ Had wheezing/whistling } & -0.026 & -0.024 & $-0.031 *$ & -0.009 & -0.002 & -0.012 \\
\hline & $(0.016)$ & $(0.016)$ & $(0.017)$ & $(0.018)$ & $(0.018)$ & $(0.023)$ \\
\hline \multicolumn{7}{|l|}{ Panel B: Children aged 2-3; N=1,807 } \\
\hline \multirow[t]{2}{*}{ Ongoing health problem } & -0.021 & -0.018 & -0.027 & -0.013 & -0.022 & -0.005 \\
\hline & $(0.023)$ & $(0.023)$ & $(0.025)$ & $(0.025)$ & $(0.025)$ & $(0.032)$ \\
\hline \multirow[t]{2}{*}{$>1$ health problem } & -0.017 & -0.017 & $-0.022 *$ & -0.014 & -0.016 & -0.013 \\
\hline & $(0.012)$ & $(0.012)$ & $(0.013)$ & $(0.014)$ & $(0.014)$ & $(0.018)$ \\
\hline \multirow[t]{2}{*}{ Hearing problems/ear infections } & $-0.020 *$ & $-0.021 * *$ & $-0.023 * *$ & -0.018 & $-0.020 *$ & -0.010 \\
\hline & $(0.011)$ & $(0.011)$ & $(0.011)$ & $(0.012)$ & $(0.012)$ & $(0.016)$ \\
\hline \multirow[t]{2}{*}{ Diagnosed asthma } & $-0.027 *$ & $-0.025^{*}$ & -0.026 & -0.028 & -0.021 & -0.007 \\
\hline & $(0.015)$ & $(0.015)$ & $(0.016)$ & $(0.018)$ & $(0.018)$ & $(0.023)$ \\
\hline \multicolumn{7}{|l|}{ Panel C: Children aged 4-5; N=1,764 } \\
\hline \multirow[t]{2}{*}{ Ongoing health problem } & -0.033 & -0.028 & -0.041 & -0.039 & -0.040 & $-0.060^{*}$ \\
\hline & $(0.024)$ & $(0.024)$ & $(0.026)$ & $(0.026)$ & $(0.026)$ & $(0.033)$ \\
\hline \multirow[t]{2}{*}{$>1$ health problem } & $-0.048 * * *$ & $-0.047 * * *$ & $-0.047 * * *$ & $-0.052 * * *$ & $-0.059 * * *$ & $-0.064 * * *$ \\
\hline & $(0.015)$ & $(0.015)$ & $(0.017)$ & $(0.017)$ & $(0.017)$ & $(0.022)$ \\
\hline \multirow[t]{2}{*}{ Vision problems } & $-0.017 *$ & $-0.016^{*}$ & -0.015 & $-0.021 * *$ & $-0.018 *$ & -0.012 \\
\hline & $(0.009)$ & $(0.009)$ & $(0.010)$ & $(0.010)$ & $(0.010)$ & $(0.013)$ \\
\hline \multirow[t]{2}{*}{ Hearing problems/ear infections } & -0.015 & -0.014 & -0.016 & -0.016 & -0.013 & -0.012 \\
\hline & $(0.011)$ & $(0.011)$ & $(0.011)$ & $(0.012)$ & $(0.012)$ & $(0.016)$ \\
\hline \multirow[t]{2}{*}{ Diagnosed asthma } & -0.027 & -0.024 & -0.020 & -0.034 & -0.029 & -0.013 \\
\hline & $(0.019)$ & $(0.019)$ & $(0.021)$ & $(0.021)$ & $(0.022)$ & $(0.027)$ \\
\hline \multicolumn{7}{|l|}{ Panel D: Children aged 6-7; N=1,731 } \\
\hline \multirow[t]{2}{*}{ Ongoing health problem } & -0.012 & -0.014 & -0.024 & -0.021 & -0.015 & 0.005 \\
\hline & $(0.025)$ & $(0.025)$ & $(0.027)$ & $(0.027)$ & $(0.028)$ & $(0.035)$ \\
\hline \multirow[t]{2}{*}{$>1$ health problem } & $-0.034 *$ & $-0.033^{*}$ & -0.030 & -0.031 & -0.030 & -0.036 \\
\hline & $(0.018)$ & $(0.018)$ & $(0.020)$ & $(0.020)$ & $(0.020)$ & $(0.025)$ \\
\hline \multirow[t]{2}{*}{ Vision problems } & -0.022 & -0.022 & -0.021 & $-0.028 *$ & -0.024 & -0.010 \\
\hline & $(0.014)$ & $(0.014)$ & $(0.015)$ & $(0.015)$ & $(0.015)$ & $(0.019)$ \\
\hline \multirow[t]{2}{*}{ Hearing problems/ear infections } & -0.011 & -0.010 & -0.003 & -0.007 & -0.007 & 0.002 \\
\hline & $(0.013)$ & $(0.013)$ & $(0.015)$ & $(0.015)$ & $(0.015)$ & $(0.019)$ \\
\hline \multirow[t]{2}{*}{ Diagnosed asthma } & 0.014 & 0.013 & 0.028 & 0.003 & 0.008 & 0.027 \\
\hline & $(0.022)$ & $(0.022)$ & $(0.023)$ & $(0.024)$ & $(0.024)$ & $(0.030)$ \\
\hline Demographic controls & $\checkmark$ & $\checkmark$ & $\checkmark$ & $\checkmark$ & $\checkmark$ & $\checkmark$ \\
\hline Health behaviour during pregnancy & & $\checkmark$ & $\checkmark$ & & $\checkmark$ & $\checkmark$ \\
\hline Employer characteristics & & & $\boldsymbol{V}$ & & & $\checkmark$ \\
\hline
\end{tabular}

Source: Longitudinal study of Australian children (LSAC).

Notes: Each coefficient is obtained from a separate regression. Matching estimator uses kernel-based matching algorithm and trims $10 \%$ of the observations, see Table 3. Variables included in each specification are listed in Table 2. Cluster-robust standard errors in parentheses. $* * * p<0.01, * * p<0.05, * p<0.1$. 
Table 5: Association of leave eligibility with child health including transmission mechanisms all

\begin{tabular}{|c|c|c|c|c|c|}
\hline & OLS (1) & OLS (2) & OLS (3) & OLS (4) & OLS (5) \\
\hline \multicolumn{6}{|l|}{ Panel A: Children aged $0-1 ; \mathrm{N}=1,850$} \\
\hline \multirow[t]{2}{*}{ Ongoing health problem } & -0.005 & -0.003 & -0.002 & -0.002 & 0.001 \\
\hline & $(0.023)$ & $(0.023)$ & $(0.023)$ & $(0.023)$ & $(0.023)$ \\
\hline \multirow[t]{2}{*}{$>1$ health problem } & $-0.025 * *$ & $-0.024 * *$ & $-0.026 * *$ & $-0.025 * *$ & $-0.025 * *$ \\
\hline & $(0.011)$ & $(0.011)$ & $(0.011)$ & $(0.011)$ & $(0.012)$ \\
\hline \multirow[t]{2}{*}{ Vision problems } & -0.000 & -0.000 & -0.000 & -0.000 & -0.000 \\
\hline & $(0.007)$ & $(0.007)$ & $(0.007)$ & $(0.007)$ & $(0.007)$ \\
\hline \multirow[t]{2}{*}{ Hearing problems/ear infections } & -0.007 & -0.006 & -0.007 & -0.006 & -0.006 \\
\hline & $(0.009)$ & $(0.009)$ & $(0.009)$ & $(0.009)$ & $(0.009)$ \\
\hline \multirow[t]{2}{*}{ Had wheezing/whistling } & $-0.031 *$ & $-0.029 *$ & $-0.033^{*}$ & -0.028 & $-0.028^{*}$ \\
\hline & $(0.017)$ & $(0.017)$ & $(0.017)$ & $(0.017)$ & $(0.017)$ \\
\hline \multicolumn{6}{|l|}{ Panel B: Children aged 2-3; N=1,807 } \\
\hline \multirow[t]{2}{*}{ Ongoing health problem } & -0.027 & -0.026 & -0.029 & -0.025 & -0.026 \\
\hline & $(0.025)$ & $(0.025)$ & $(0.025)$ & $(0.025)$ & $(0.025)$ \\
\hline \multirow[t]{2}{*}{$>1$ health problem } & $-0.022 *$ & $-0.022 *$ & $-0.022 *$ & -0.021 & -0.021 \\
\hline & $(0.013)$ & $(0.013)$ & $(0.013)$ & $(0.013)$ & $(0.013)$ \\
\hline \multirow[t]{2}{*}{ Hearing problems/ear infections } & $-0.023 * *$ & $-0.022 * *$ & $-0.023 * *$ & $-0.021 *$ & $-0.021 *$ \\
\hline & $(0.011)$ & $(0.011)$ & $(0.011)$ & $(0.011)$ & $(0.011)$ \\
\hline \multirow[t]{2}{*}{ Diagnosed asthma } & -0.026 & -0.024 & -0.026 & -0.023 & -0.022 \\
\hline & $(0.016)$ & $(0.016)$ & $(0.016)$ & $(0.016)$ & $(0.016)$ \\
\hline \multicolumn{6}{|l|}{ Panel C: Children aged 4-5; N=1,764 } \\
\hline \multirow[t]{2}{*}{ Ongoing health problem } & -0.041 & -0.040 & $-0.043 *$ & -0.042 & $-0.044 *$ \\
\hline & $(0.026)$ & $(0.026)$ & $(0.026)$ & $(0.026)$ & $(0.026)$ \\
\hline \multirow[t]{2}{*}{$>1$ health problem } & $-0.047 * * *$ & $-0.046 * * *$ & $-0.048 * * *$ & $-0.046 * * *$ & $-0.047 * * *$ \\
\hline & $(0.017)$ & $(0.017)$ & $(0.017)$ & $(0.017)$ & $(0.017)$ \\
\hline \multirow[t]{2}{*}{ Vision problems } & -0.015 & -0.015 & -0.015 & -0.015 & -0.015 \\
\hline & $(0.010)$ & $(0.010)$ & $(0.010)$ & $(0.010)$ & $(0.010)$ \\
\hline \multirow[t]{2}{*}{ Hearing problems/ear infections } & -0.016 & -0.016 & -0.018 & -0.015 & -0.017 \\
\hline & $(0.011)$ & $(0.011)$ & $(0.011)$ & $(0.012)$ & $(0.011)$ \\
\hline \multirow[t]{2}{*}{ Diagnosed asthma } & -0.020 & -0.018 & -0.024 & -0.019 & -0.021 \\
\hline & $(0.021)$ & $(0.021)$ & $(0.021)$ & $(0.021)$ & $(0.021)$ \\
\hline \multicolumn{6}{|l|}{ Panel D: Children aged 6-7; N=1,731 } \\
\hline \multirow[t]{2}{*}{ Ongoing health problem } & -0.024 & -0.022 & -0.023 & & -0.021 \\
\hline & $(0.027)$ & $(0.027)$ & $(0.027)$ & & $(0.027)$ \\
\hline \multirow[t]{2}{*}{$>1$ health problem } & -0.030 & -0.030 & -0.027 & & -0.027 \\
\hline & $(0.020)$ & $(0.020)$ & $(0.020)$ & & $(0.020)$ \\
\hline \multirow[t]{2}{*}{ Vision problems } & -0.021 & -0.020 & -0.019 & & -0.018 \\
\hline & $(0.015)$ & $(0.015)$ & $(0.015)$ & & $(0.015)$ \\
\hline \multirow[t]{2}{*}{ Hearing problems/ear infections } & -0.003 & -0.003 & -0.002 & & -0.002 \\
\hline & $(0.015)$ & $(0.015)$ & $(0.015)$ & & $(0.015)$ \\
\hline \multirow[t]{2}{*}{ Diagnosed asthma } & 0.028 & 0.031 & 0.028 & & 0.031 \\
\hline & $(0.023)$ & $(0.023)$ & $(0.023)$ & & $(0.023)$ \\
\hline Specification with 3 sets of controls & $\boldsymbol{V}$ & $\checkmark$ & $\checkmark$ & $\checkmark$ & $\boldsymbol{V}$ \\
\hline Breastfeeding & & $\boldsymbol{\nu}$ & & & $\boldsymbol{\sim}$ \\
\hline Parental health & & & $\boldsymbol{\nu}$ & & $\boldsymbol{V}$ \\
\hline Childcare & & & & $\checkmark$ & $\boldsymbol{\gamma}$ \\
\hline
\end{tabular}

Source: Longitudinal study of Australian children (LSAC), own calculations

Notes: Each coefficient is obtained from a separate regression. Variables included in each specification are listed in Table 2. The indicators for transmission mechanisms are jointly significant at the 10\%-level for 23 out of 71 regressions. Cluster-robust standard errors in parentheses. $* * * p<0.01, * * p<0.05$, * $p<0.1$. 
Table 6: Association of leave eligibility with child health, by parental socio-economic status

\begin{tabular}{|c|c|c|c|c|}
\hline Child aged: & $0-1$ & $2-3$ & $4-5$ & $6-7$ \\
\hline \multirow[t]{2}{*}{ Mother high income } & -0.020 & -0.026 & -0.045 & -0.023 \\
\hline & $(0.019)$ & $(0.021)$ & $(0.028)$ & $(0.034)$ \\
\hline $\mathrm{N}$ & 832 & 817 & 800 & 788 \\
\hline \multirow[t]{2}{*}{ Mother low income } & $-0.028 *$ & -0.023 & $-0.053 * *$ & -0.030 \\
\hline & $(0.015)$ & $(0.018)$ & $(0.022)$ & $(0.026)$ \\
\hline $\mathrm{N}$ & 1018 & 990 & 964 & 943 \\
\hline \multirow[t]{2}{*}{ Father high income } & -0.027 & -0.022 & -0.026 & -0.017 \\
\hline & $(0.017)$ & $(0.019)$ & $(0.026)$ & $(0.030)$ \\
\hline $\mathrm{N}$ & 805 & 782 & 773 & 757 \\
\hline \multirow[t]{2}{*}{ Father low income } & -0.019 & -0.007 & $-0.063 * * *$ & -0.041 \\
\hline & $(0.016)$ & $(0.019)$ & $(0.024)$ & $(0.029)$ \\
\hline $\mathrm{N}$ & 951 & 932 & 906 & 890 \\
\hline \multirow[t]{2}{*}{ Family high income } & -0.028 & -0.028 & -0.037 & -0.017 \\
\hline & $(0.018)$ & $(0.021)$ & $(0.029)$ & $(0.033)$ \\
\hline $\mathrm{N}$ & 783 & 762 & 752 & 740 \\
\hline \multirow[t]{2}{*}{ Family low income } & -0.023 & -0.012 & $-0.062 * * *$ & $-0.045^{*}$ \\
\hline & $(0.015)$ & $(0.018)$ & $(0.023)$ & $(0.027)$ \\
\hline $\mathrm{N}$ & 973 & 952 & 927 & 907 \\
\hline \multirow[t]{2}{*}{ Mother tertiary education } & -0.007 & -0.020 & $-0.051 *$ & -0.034 \\
\hline & $(0.019)$ & $(0.019)$ & $(0.028)$ & $(0.032)$ \\
\hline $\mathrm{N}$ & 858 & 833 & 818 & 808 \\
\hline \multirow[t]{2}{*}{ Mother no tertiary education } & $-0.042 * * *$ & -0.019 & $-0.043 * *$ & -0.034 \\
\hline & $(0.014)$ & $(0.018)$ & $(0.021)$ & $(0.027)$ \\
\hline $\mathrm{N}$ & 992 & 974 & 946 & 923 \\
\hline \multirow[t]{2}{*}{ Father tertiary education } & 0.002 & -0.005 & -0.016 & -0.054 \\
\hline & $(0.022)$ & $(0.026)$ & $(0.034)$ & $(0.037)$ \\
\hline $\mathrm{N}$ & 603 & 581 & 575 & 564 \\
\hline \multirow[t]{2}{*}{ Father no tertiary education } & $-0.036 * *$ & -0.024 & $-0.067 * * *$ & -0.027 \\
\hline & $(0.014)$ & $(0.016)$ & $(0.021)$ & $(0.026)$ \\
\hline $\mathrm{N}$ & 1153 & 1133 & 1104 & 1083 \\
\hline
\end{tabular}

Source: Longitudinal study of Australian children (LSAC).

Notes: Dependent variable: if child has multiple health problems (0/1). Each coefficient is obtained from a separate linear probability model controlling for all variables contained in specification 3 (see Table 2 for descriptives). Cluster-robust standard errors in parentheses. $* * * p<0.01, * * p<0.05, * p<0.1$. 
Figure 1: Breastfeeding duration by eligibility for paid parental leave - kernel density

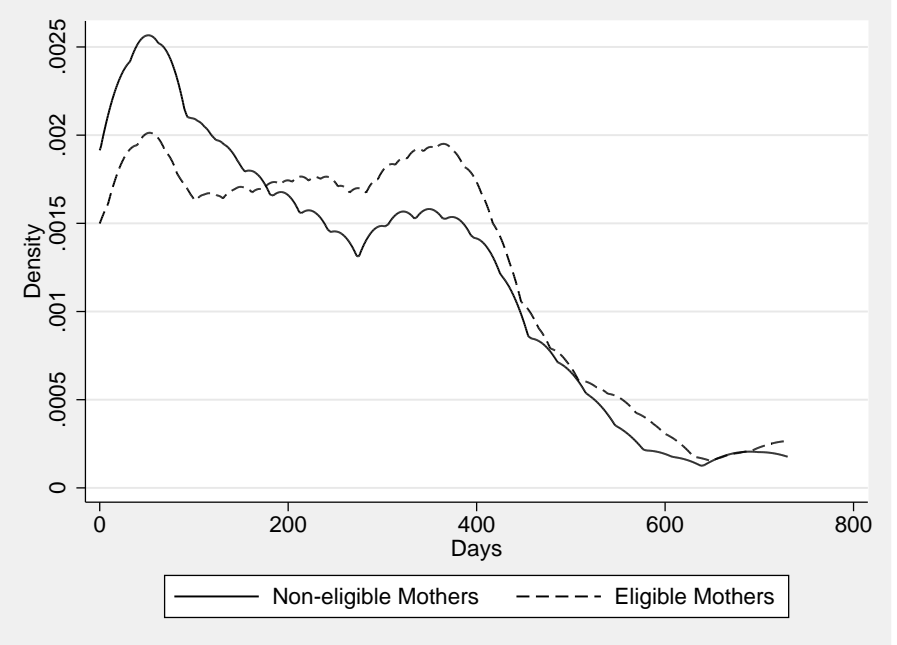


Figure A1: Propensity score distributions by treatment status, child aged 0-1.

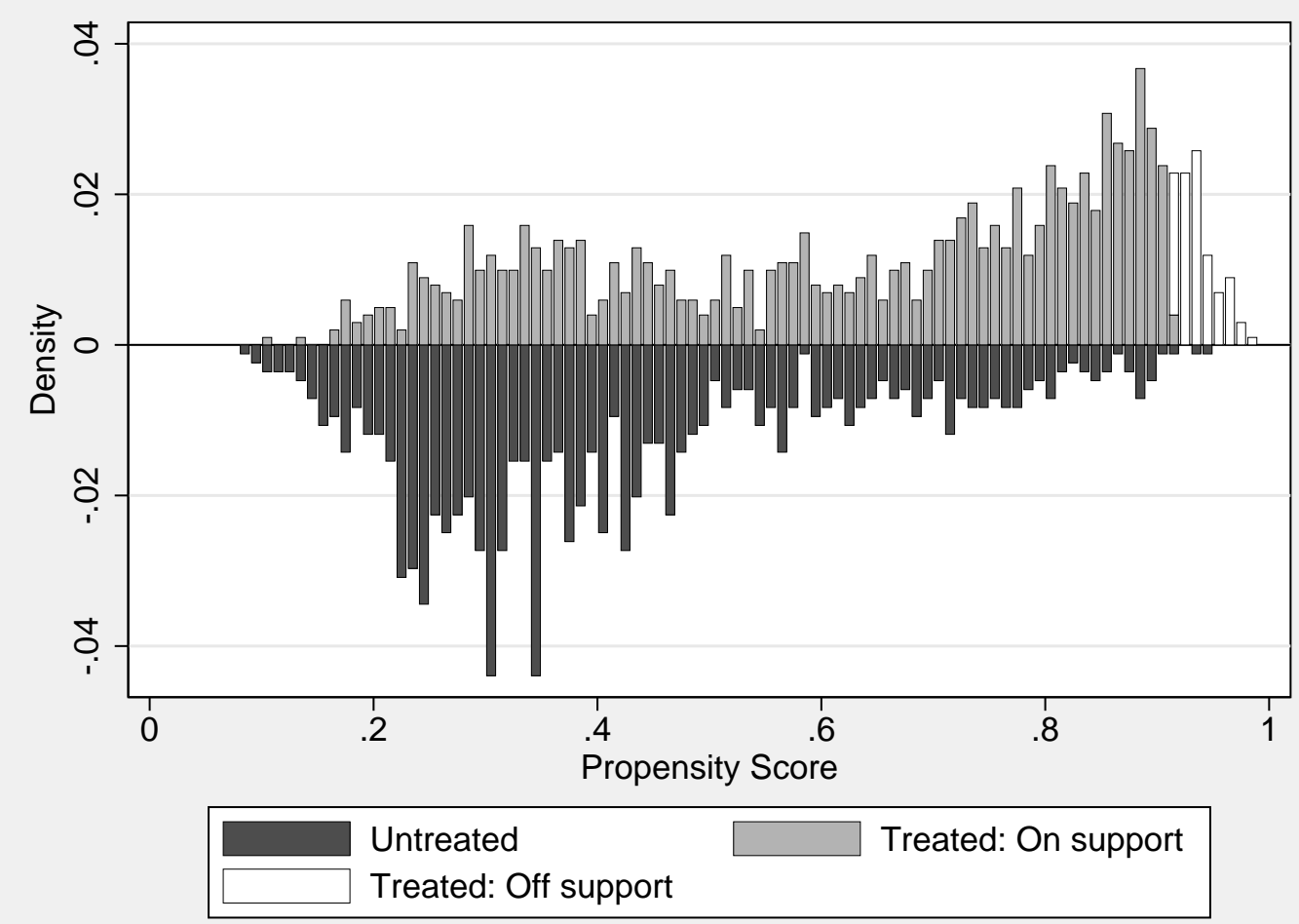


Table A1: Descriptive statistics for breastfeeding by eligibility status

\begin{tabular}{lrrr}
\hline & not eligible & eligible & p-value \\
\hline Breastfed more than 2 weeks & 85.850 & 88.980 & 0.001 \\
Breastfed more than 4 weeks & 81.400 & 85.670 & 0.000 \\
Breastfed more than 13 weeks & 62.310 & 70.820 & 0.000 \\
Breastfed more than 26 weeks & 45.060 & 53.540 & 0.000 \\
Breastfed more than 39 weeks & 33.570 & 38.910 & 0.000 \\
Breastfed more than 52 weeks & 18.710 & 23.210 & 0.000 \\
\hline $\mathrm{N}$ & 842 & 1008 & \\
\hline
\end{tabular}

Source: Longitudinal study of Australian children (LSAC), own calculations 
Table A2: Association of leave eligibility with child health including transmission mechanisms - only children with at least one parent without tertiary qualification

\begin{tabular}{|c|c|c|c|c|c|}
\hline & OLS (1) & OLS (2) & OLS (3) & OLS (4) & OLS (5) \\
\hline \multicolumn{6}{|l|}{ Panel A: Children aged $0-1 ; \mathrm{N}=1,391$} \\
\hline \multirow[t]{2}{*}{ Ongoing health problem } & -0.002 & -0.001 & -0.002 & 0.000 & 0.002 \\
\hline & $(0.027)$ & $(0.027)$ & $(0.027)$ & $(0.026)$ & $(0.027)$ \\
\hline \multirow[t]{2}{*}{$>1$ health problem } & $-0.033 * *$ & $-0.032 * *$ & $-0.034 * * *$ & $-0.031 * *$ & $-0.033 * *$ \\
\hline & $(0.013)$ & $(0.013)$ & $(0.013)$ & $(0.013)$ & $(0.013)$ \\
\hline \multirow[t]{2}{*}{ Vision problems } & 0.000 & 0.001 & 0.000 & 0.000 & 0.001 \\
\hline & $(0.008)$ & $(0.008)$ & $(0.008)$ & $(0.008)$ & $(0.008)$ \\
\hline \multirow[t]{2}{*}{ Hearing problems/ear infections } & -0.010 & -0.010 & -0.012 & -0.009 & -0.010 \\
\hline & $(0.011)$ & $(0.011)$ & $(0.011)$ & $(0.011)$ & $(0.011)$ \\
\hline \multirow[t]{2}{*}{ Had wheezing/whistling } & $-0.037 *$ & $-0.034 *$ & $-0.039 * *$ & $-0.033^{*}$ & $-0.034 *$ \\
\hline & $(0.020)$ & $(0.020)$ & $(0.020)$ & $(0.020)$ & $(0.020)$ \\
\hline \multicolumn{6}{|l|}{ Panel B: Children aged 2-3; N=1,364 } \\
\hline \multirow[t]{2}{*}{ Ongoing health problem } & -0.037 & -0.035 & -0.036 & -0.034 & -0.033 \\
\hline & $(0.028)$ & $(0.028)$ & $(0.028)$ & $(0.028)$ & $(0.028)$ \\
\hline \multirow[t]{2}{*}{$>1$ health problem } & $-0.030 * *$ & $-0.030 * *$ & $-0.030 * *$ & $-0.029 *$ & $-0.029 *$ \\
\hline & $(0.015)$ & $(0.015)$ & $(0.015)$ & $(0.015)$ & $(0.015)$ \\
\hline \multirow[t]{2}{*}{ Hearing problems/ear infections } & $-0.026 * *$ & $-0.026 * *$ & $-0.026 * *$ & $-0.025^{*}$ & $-0.024 *$ \\
\hline & $(0.013)$ & $(0.013)$ & $(0.013)$ & $(0.013)$ & $(0.013)$ \\
\hline \multirow[t]{2}{*}{ Diagnosed asthma } & -0.018 & -0.016 & -0.019 & -0.015 & -0.014 \\
\hline & $(0.019)$ & $(0.019)$ & $(0.020)$ & $(0.019)$ & $(0.019)$ \\
\hline \multicolumn{6}{|l|}{ Panel C: Children aged 4-5; $N=1,330$} \\
\hline \multirow[t]{2}{*}{ Ongoing health problem } & -0.026 & -0.026 & -0.029 & -0.028 & -0.031 \\
\hline & $(0.029)$ & $(0.029)$ & $(0.029)$ & $(0.029)$ & $(0.029)$ \\
\hline \multirow[t]{2}{*}{$>1$ health problem } & $-0.054 * * *$ & $-0.054 * * *$ & $-0.058 * * *$ & $-0.053 * * *$ & $-0.055 * * *$ \\
\hline & $(0.019)$ & $(0.019)$ & $(0.018)$ & $(0.019)$ & $(0.018)$ \\
\hline \multirow[t]{2}{*}{ Vision problems } & -0.011 & -0.010 & -0.011 & -0.011 & -0.011 \\
\hline & $(0.012)$ & $(0.012)$ & $(0.012)$ & $(0.012)$ & $(0.012)$ \\
\hline \multirow[t]{2}{*}{ Hearing problems/ear infections } & -0.009 & -0.009 & -0.011 & -0.008 & -0.010 \\
\hline & $(0.013)$ & $(0.013)$ & $(0.013)$ & $(0.013)$ & $(0.013)$ \\
\hline \multirow[t]{2}{*}{ Diagnosed asthma } & -0.012 & -0.011 & -0.016 & -0.011 & -0.013 \\
\hline & $(0.024)$ & $(0.024)$ & $(0.024)$ & $(0.024)$ & $(0.024)$ \\
\hline \multicolumn{6}{|l|}{ Panel D: Children aged 6-7; $N=1,301$} \\
\hline \multirow[t]{2}{*}{ Ongoing health problem } & -0.030 & -0.030 & -0.031 & & -0.030 \\
\hline & $(0.031)$ & $(0.031)$ & $(0.031)$ & & $(0.031)$ \\
\hline \multirow[t]{2}{*}{$>1$ health problem } & -0.033 & -0.033 & -0.031 & & -0.031 \\
\hline & $(0.023)$ & $(0.023)$ & $(0.023)$ & & $(0.023)$ \\
\hline \multirow[t]{2}{*}{ Vision problems } & -0.024 & -0.023 & -0.022 & & -0.022 \\
\hline & $(0.017)$ & $(0.017)$ & $(0.018)$ & & $(0.018)$ \\
\hline \multirow[t]{2}{*}{ Hearing problems/ear infections } & -0.005 & -0.005 & -0.004 & & -0.004 \\
\hline & $(0.017)$ & $(0.018)$ & $(0.017)$ & & $(0.017)$ \\
\hline \multirow[t]{2}{*}{ Diagnosed asthma } & $0.053^{*}$ & $0.055 * *$ & $0.051 *$ & & $0.053 *$ \\
\hline & $(0.028)$ & $(0.027)$ & $(0.028)$ & & $(0.028)$ \\
\hline Specification with 3 sets of controls & $\boldsymbol{\nu}$ & $\checkmark$ & $\checkmark$ & $\checkmark$ & $\checkmark$ \\
\hline Breastfeeding & & $\boldsymbol{\nu}$ & & & $\boldsymbol{V}$ \\
\hline Parental health & & & $\boldsymbol{\nu}$ & & $\boldsymbol{V}$ \\
\hline Childcare & & & & $\checkmark$ & $\boldsymbol{V}$ \\
\hline
\end{tabular}

Source: Longitudinal study of Australian children (LSAC).

Notes: Each coefficient is obtained from a separate regression. Variables included in each specification are listed in Table 2. Cluster-robust standard errors in parentheses. $* * * p<0.01, * * p<0.05, * p<0.1$. 


\section{University Library}

\section{- M M I N E R VA A gateway to Melbourne's research publications}

Minerva Access is the Institutional Repository of The University of Melbourne

Author/s:

BROADWAY, B;Kalb, G;Kuehnle, D;Maeder, M

Title:

Paid Parental Leave and Child Health in Australia

Date:

2017

Citation:

BROADWAY, B., Kalb, G., Kuehnle, D. \& Maeder, M. (2017). Paid Parental Leave and Child Health in Australia. The Economic Record, 93 (301), pp.214-237. https:// doi.org/10.1111/1475-4932.12311.

Persistent Link:

http://hdl.handle.net/11343/123227 